\title{
Surface Characteristics and Printing Properties of Cotton Fabric Treated with Dielectric Barrier Discharge
}

\author{
Hend Ahmed ${ }^{1}$, M. S. Taher ${ }^{2}$, A. El-Halwagy ${ }^{1}$, A. Abdelrahman ${ }^{1}$ and A. A. \\ Garamoon $^{2}$ \\ ${ }^{1}$ Dyeing, Printing and Auxiliaries Department, Textile Research Division, National \\ Research Centre, ${ }^{2}$ Center of plasma technology, Faculty of science, Al-Azhar \\ University, Nasr city, Cairo,Egypt
}

\begin{abstract}
THE MORPHOLOGICAL surface properties of natural textile materials are important determinants of their usefulness and many of the chemical treatments in use are aimed at modifying these properties. Low temperature plasma has been used as an effective means of modifying the surface properties of natural textile fibers such as wool and cotton. This research work described the screen printing technology and plasma treatment of cotton fabrics. The morphological properties of the plasma treated fabrics were characterized by scanning electron microscopy (SEM), Fourier-transform infrared spectroscopy (FTIR), and X-ray diffraction (XRD). The coloration assessment, wettability, colorfastness and mechanical properties were also evaluated to demonstrate satisfactory results.
\end{abstract}

Keywords: Cotton; Plasma; Printing; Dielectric Barrier Discharge.

\section{Introduction}

Coverage of materials to appropriate plasma treatment can effect both chemical and physical changes on the inner layers so as to afford a more reactive surface without intrusive with the bulk properties simply due to shallow penetration depth [1-9]. Certain gas modifications of the surface layer can be achieved by pounding the surface with ions, electrons and other high-energy particles that knock the polymer material out of the surface and respectively evaporate it [10]. This part is entailed to describe the prospects for improving cotton fabric through the modification of its surface properties by plasma treatment. This is considered as a physical modification of the fabric surface. Plasma treatments of textile fibers is a fast gro- wing field and find some possible uses as an environmentally friendly process, where no chemicals are involved $[11,12]$.

\section{Experimental}

\section{Materials.}

Cotton fabric of $289 \mathrm{~g} / \mathrm{m}^{2}$ (supplied by Misr Helwan Company) was used. The fabric was scoured for 90 minutes with

$3 \mathrm{~g} / \mathrm{l}$ sodium carbonate, $0.5 \mathrm{~g} / 1$ wetting agent \&

$1 \mathrm{~g} / \mathrm{l}$ synthetic detergent. Nonionic detergent, urea and sodium carbonate were laboratory grade chemical. Reactive dye namely, Tulactiv Red P-4BNwas kindly supplied by Ciba. Commercial sodium alginate of medium viscosity type supplied by Ciba.

\section{Methods}

\section{Fabric Treatment}

The cotton fabric was exposed to low temperature plasma [dielectric barrier discharge (DBD)] using air and oxygen (purity $98 \%$ ) under atmospheric pressure. Different conditions of DBD discharge plasma (time, current, and discharge power) were applied. The exposure time ranges between 0.5 to 12 minutes, while the current ranges from 0.1 to $4 \mathrm{~mA}$. The discharge power used ranges between 0.1 to 7 watts.

\section{Plasma Apparatus}

The experimental arrangement of DBD apparatus used in textile treatment is shown in Figure (1). DBD cell consists of two electrodes of stainless steel disc has a diameter of $25.5 \mathrm{~cm}$ and thickness of $2 \mathrm{~mm}$. The lower electrode is fixed to a Perspex base of $30 \mathrm{~cm}$ diameter and 2 $\mathrm{cm}$ thickness and connected to earth. The upper electrode is fixed to a Perspex disc of $30 \mathrm{~cm}$ diameter and $1 \mathrm{~cm}$ thickness and is connected to high voltage (HV) AC power supply of 50 
$\mathrm{Hz}$ frequency and a variable voltage of $0-20 \mathrm{kV}$. A dielectric material of glass has a thickness of $1.7 \mathrm{~mm}$ was pasted to the upper electrode. The upper and lower perspex discs are connected to each other via O-ring. The gap distance (d) between dielectric glass and the lower electrode is $3 \mathrm{~mm}$. DBD treatment occurs completely in air environment. The most electrical diagnostics of the measurement of the voltage applied to the electrode and the resultant discharge current was displayed on a two channel digital time memory oscilloscope by using 2000:1 resistive potential divider. The discharge current flow through DBD cell was measured as a voltage across a resistor of $1 \mathrm{k} \Omega$ which was connected in series to the ground and also displayed on the oscilloscope. printing technique. After air drying, the samples were, steamed for 5-15 minutes at $102{ }^{\circ} \mathrm{C}$. Then washed according to the following steps:

- Rinsing thoroughly with cold water.

- Treatment with hot water.

- Treatment near the boiling temperature (90$95^{\circ} \mathrm{C}$ ) with $2 \mathrm{~g} / 1$ nonionic detergent.

- Washing with hot water.

- Rinsing with cold water.

Finally the samples were dried and assessed for color strength and fastness properties.

\section{Measurements \\ $\%$ Weight Loss}

The weight of polyester samples before and after plasma treatment was measured. Weight loss ( $\%$ ) was

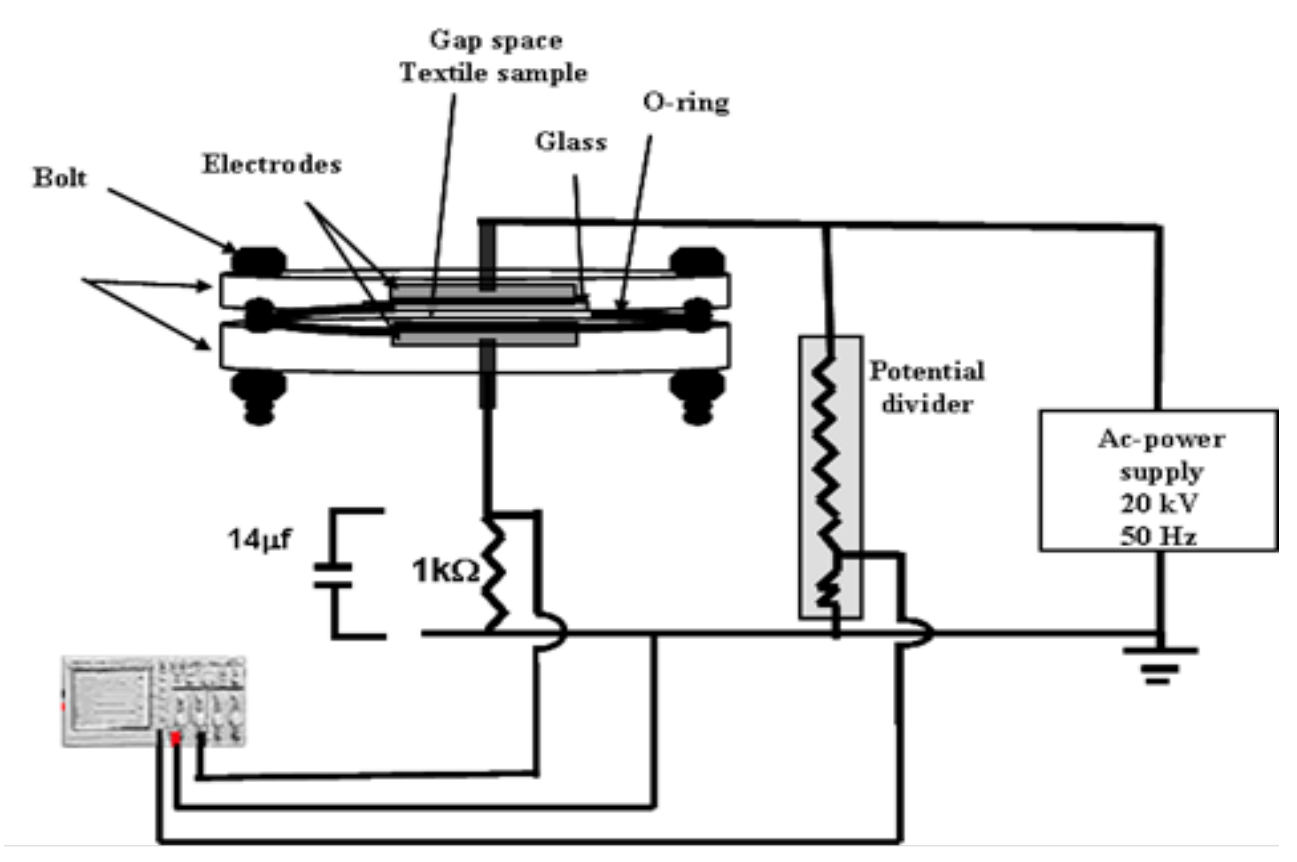

Fig. 1. Experimental setup of DBD.

Preparation of Printing Paste

The printing paste was prepared according to the following recipe:

$\begin{array}{lcc}\text { Alginate stock } & 400-600 & \mathrm{~g} \\ \text { Urea } & 50-100 & \mathrm{~g} \\ \text { Tulactive dye } & 40 & \mathrm{~g} \\ \text { Sodium carbonate } & 25-30 & \mathrm{~g} \\ \text { Water to make up to } & 1000 & \mathrm{~g}\end{array}$

Stock thickening:

Alginate stock

$\begin{array}{ll}\text { Sodium alginate } & 30-12 \mathrm{~g} \\ \text { Water to make up to } & 1000 \mathrm{~g}\end{array}$

\section{Printing Technique}

Samples of treated and untreated cotton fabric were printed using conventional silk screen determined from the weight difference as follows:

Weight loss $(\%)=(\mathrm{W} 0-\mathrm{W} 1 / \mathrm{W} 0) \times 100$ where W0 and W1 are the weights of PET fabric before and after plasma treatment respectively [108].

\section{Whiteness}

Changes in fabric whiteness after plasma exposure were measured with an Elrepho 2000 Reflectance Spectrophotometer (Data Color International) according to AATCC test method 153-1985.

\section{Wettability}

The wettability was evaluated by measuring the wetting time according to the AATCC method [109].A drop of water is allowed to fall from a fixed hight onto the surface of PET fabric under examination. The time that has been taken for the 
drop of water to disappear has been measured and taken as wetting time, and the results were the average value of four readings.

\section{Tensile Strength}

Fabric tensile strength test was conducted according to ASTM method, which is standard test method for breaking force and elongation of textile fabrics [110].

\section{$X$-Ray Crystallinity}

X- Ray crystallinity was measured with a PW 3710 diffractometer (Phillips) (XRD) using Cuk $\alpha$ radiation at an operating voltage of $40 \mathrm{Kv}$ and a current of $35 \mathrm{~mA}$ from 5 to 60 angles. Pellets were prepared from $0.25 \mathrm{gm}$ fiber and crystalline size was calculated from the equation.

$$
\mathrm{t}=\mathrm{k} \lambda / \beta \cos \theta
$$

where $\mathrm{t}=$ the size of crystal $(\AA), \mathrm{k}=$ shape factor (0.94), $\lambda=$ wave length of $x$-ray $(1.542 \AA), \beta=$ halfwidth (radian), $\theta=$ Bragg angle $(0)$

\section{Scanning Electron Microscope (SEM)}

The untreated and plasma treated fabrics were investigated by a Scanning Electron Microscope (SEM) JSMT-20, JEOL-Japan, magnification range $1500-2000 \mathrm{x}$, resolution $200 \mathrm{~A}^{\circ}$, and accelerating voltage $19 \mathrm{kV}$. Before examinations, the fabric surface was prepared on an appropriate disk and coated randomly by a spray of gold. These investigations were carried out at the department of physical chemistry, NRC.

Fourier-Transition Infrared Spectroscopy (FTIR)

Fourier- transition infrared spectroscopy (FTIR) was performed using a Pye-Unicam spectra-1000 machine to determine the functional groups on the surface of the PET samples. Potassium bromide $(\mathrm{KBr})$ disc was used.

\section{Color assessment}

The color yield $(\mathrm{K} / \mathrm{S})$ of each printed sample was measured using a Data Color SF 600plus Colorimeter using a measured area with diameter of $9 \mathrm{~mm}$. All the $(\mathrm{K} / \mathrm{S})$ values were calculated by subtracting the $(\mathrm{K} / \mathrm{S})$ value of the printed untreated sample from the $(\mathrm{K} / \mathrm{S})$ values of the printed treated samples. (i.e values obtained are relative color strength)

\section{Handle}

Changes in roughness values were measured for the printed untreated and treated PET samples using a surface roughness measuring instrument SE1700 $\alpha$. The results obtained were the average values of three readings.

Fastness Properties

The AATCC Test Method 16-2001 (color fastness to light), AATCC Test Method 612001 (color fastness to laundering) and AATCC
Test Method 8-2001 (color fastness to rubbing) assessed the color fastness of the printed fabrics.

\section{Results and discussion}

The surface of polymer substrate can be adjust by using low temperature plasma through the physical and the chemical properties are change for example., grafting, cross linking, etching... etc. The weight loss behavior of cotton is affected by the plasma treatment. The result of air and oxygen plasma treatment time for the percentage weight loss of cotton fabric is shown in Figures 2, 3 and 4,5 respectively. This treatment is carried out at different levels of discharge power. Both treatment time and discharge power affect the $\%$ weight loss of treated cotton fabric. It is generally noticed that, plasma increased \% weight loss for treated fabric dramatically with exposure time up to a certain limit and then it either become constant or decreases. These changes are referred to the reactivity of the fabric surface obtained due to plasma etching.

In case of air plasma, at lower discharge power (0.1- 0.4 watts), the maximum weight loss is obtained after 7 minutes of exposure time and over this limit it nearly reached a steady state. While, at higher discharge power (2-7 watts), the maximum limit obtained after 5 minutes of exposure time and more than that, the \%weight loss decreased. Similar behavior is obtained when using oxygen plasma. Generally speaking, the percent weight loss results obtained are very small where it ranges between $0.1-0.8 \%$ for both air and oxygen plasmas.

\section{Wettability}

The effect of plasma exposure time on the wettability of cotton fabric treated with air and oxygen was studied by applying different levels of discharge power. The results obtained are illustrated in Figures 6, 7 and 8, 9 respectively. In general, it is noticed that, there is a sharp decrease in wetting time of the treated fabric $(\approx 50 \%$ of the blank) carried out at 1 minute of plasma treatment (regardless of gas type and power level). The wetting time is continued in decrease step by step as increasing the treatment time for the samples treated at discharge powers $0.1-0.4$ and $0.1-0.35$ watts for both air and oxygen plasmas respectively as shown in Figures $6 \& 8$. This means that plasma treatment improves the hydrophilic properties of cotton by inducing polar functional groups which increase the surface free energy of the fiber and decrease the contact angle, i.e. the plasma treatment increases the wettability of the fiber. At higher discharge powers 2-7 and 1-8 watts (Figures $8 \& 9$ ), the same phenomenon holds true but up to a certain limit of treatment time a bout 5 minutes and more over that the opposite is carried out, i.e. the wetting time increases and wettability decrease due to the increase in the crystalinity of the fabric which increased at higher discharge power as mentioned before. The oxygen plasma has more effect and gives higher values than air plasma; 


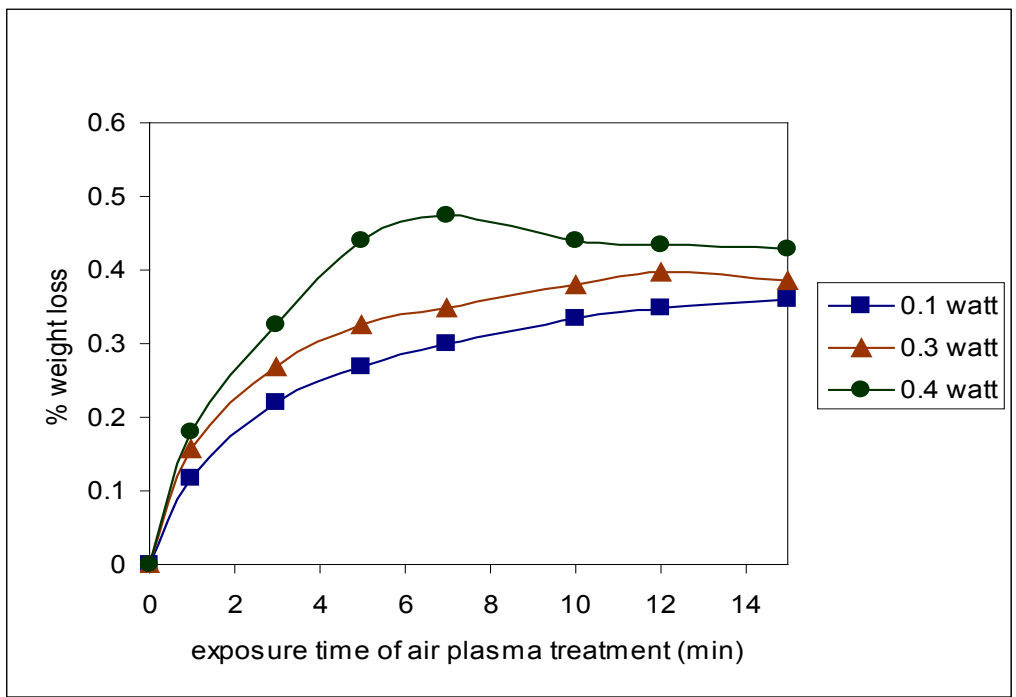

Fig. 2. Effect of air plasma treatment time on the \% weight loss of cotton fabric treated at discharge powers 0.1 , $0.3,0.4$ watts.

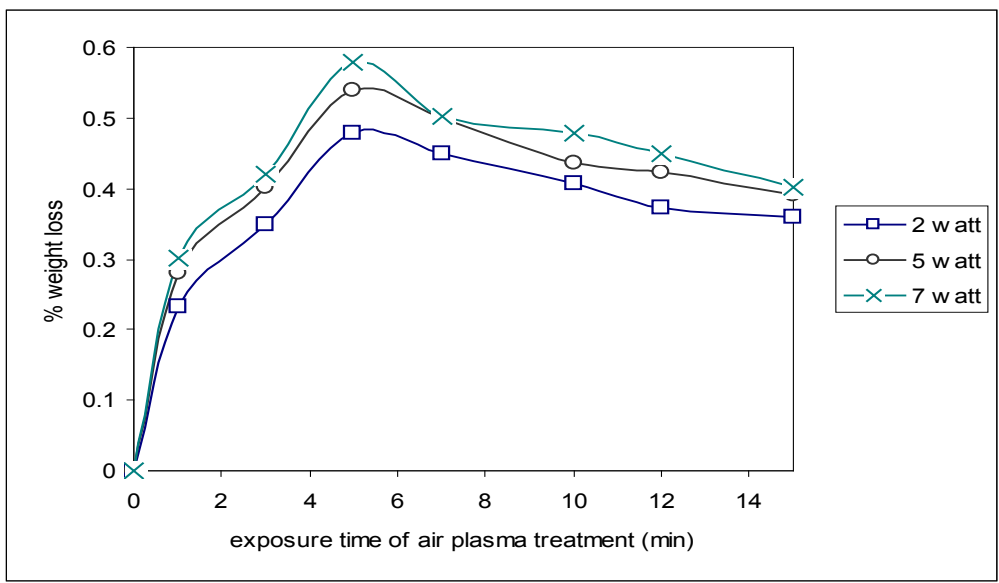

Fig. 3. Effect of air plasma treatment time on the \% weight loss of cotton fabric treated at discharge powers 2, 5, 7 watts.

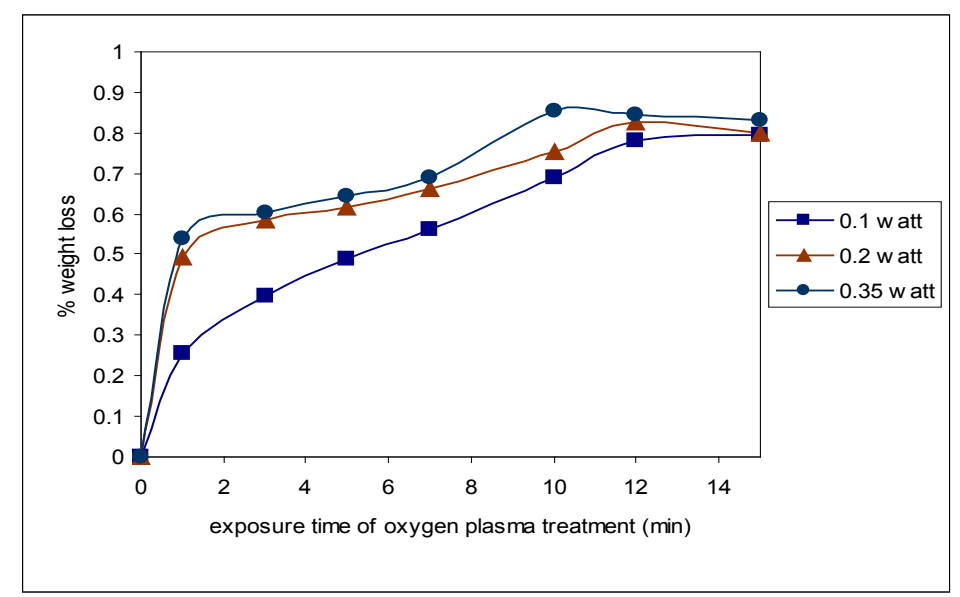

Fig. 4. Effect of oxygen plasma treatment time on the $\%$ weight loss of cotton fabric treated at discharge powers $0.1,0.2,0.35$ watts.

J. Text. Color. Polym. Sci. 16, No. 2 (2019) 


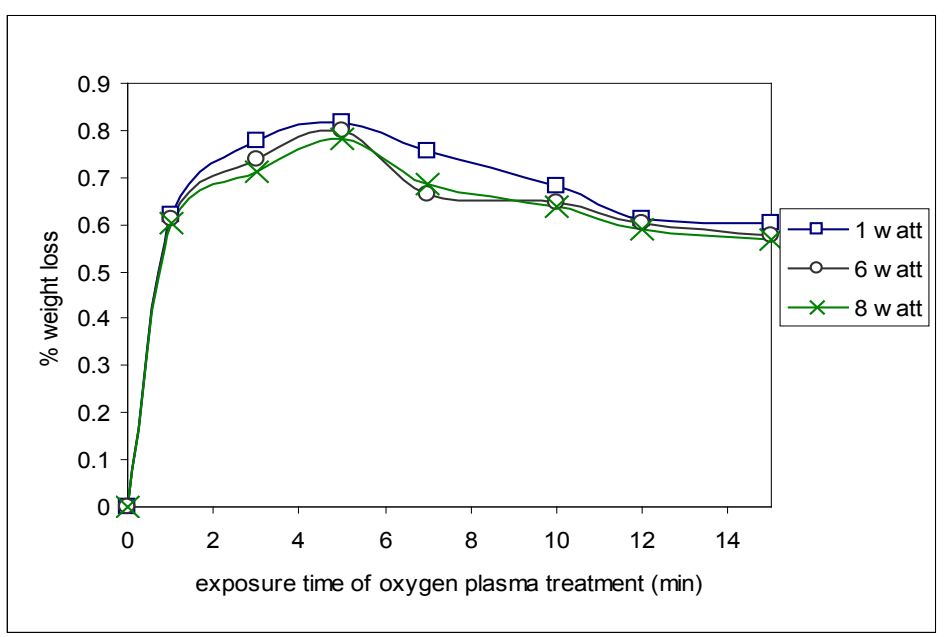

Fig. 5. Effect of oxygen plasma treatment time on the \% weight loss of cotton fabric treated at discharge powers $1,6,8$ watts.

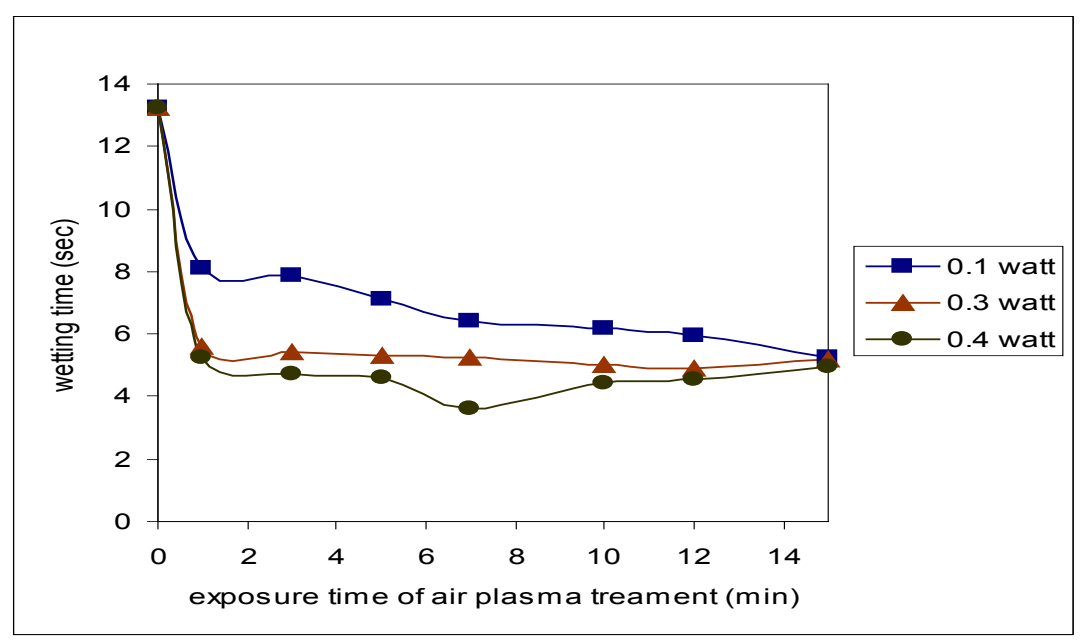

Fig. 6. Wetting time of treated cotton fabrics versus air plasma exposure time under atmospheric pressure at discharge powers $0.1,0.3,0.4$ watts.

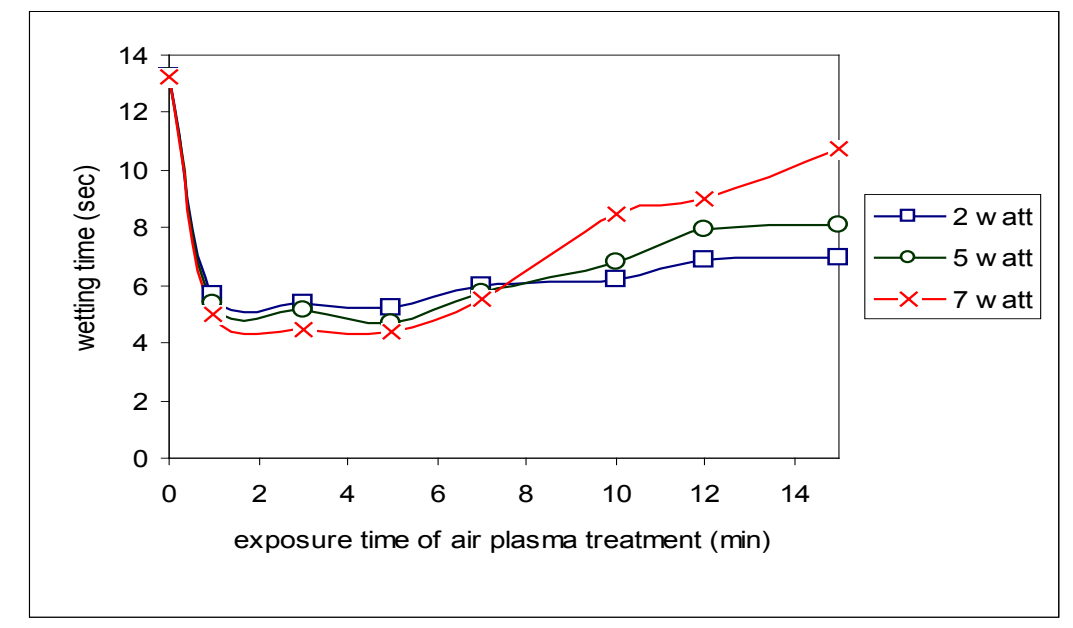

Fig. 7. Wetting time of treated cotton fabrics versus air plasma exposure time under atmospheric pressure at discharge powers $2,5,7$ watts. 


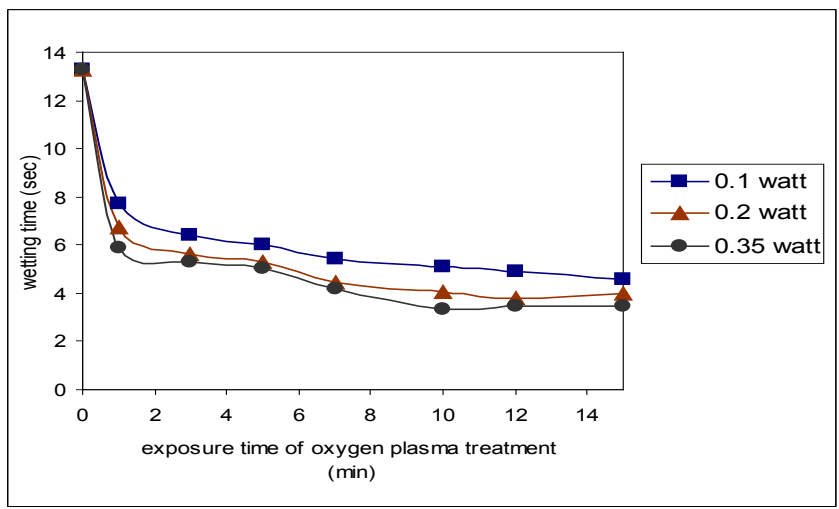

Fig. 8. Wetting time of treated cotton fabrics versus oxygen plasma exposure time under atmospheric pressure at discharge powers $0.1,0.2,0.35$ watts.

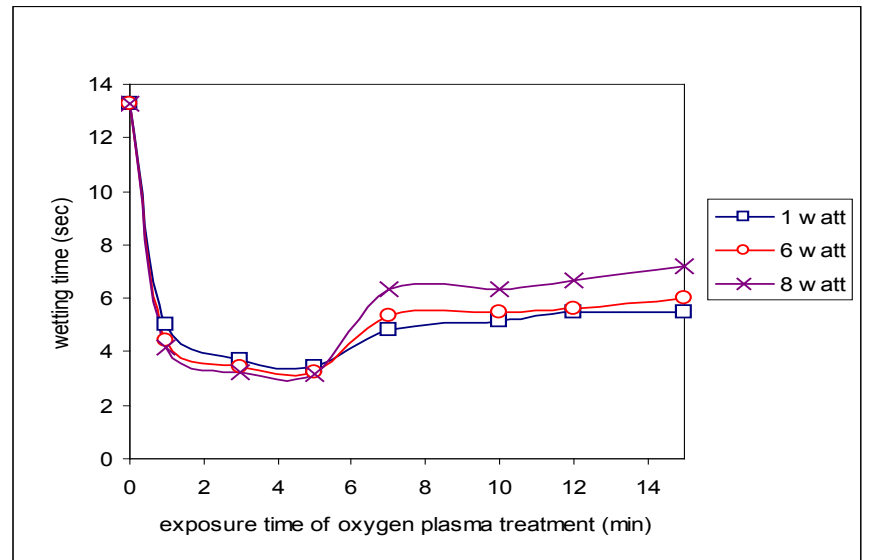

Fig. 9. Wetting time of treated cotton fabrics versus oxygen plasma exposure time under atmospheric pressure at discharge powers $1,6,8$ watts.

\section{Tensile Strength}

Table I and II represent the tensile strength data for air and oxygen plasma treated cotton fabric under atmospheric, respectively. Figures 10, 11 and 12, 13 illustrate the relation between fabric strength and treatment time with both air and oxygen plasma. Regardless of treatment time and level of discharge power, it is clear that, the tensile strength of cotton fabric increases suddenly in the first stage of plasma pre-treatments (i.e. at 1 minute) and then decreases. This finial growth of strength may be due to the consequence caused by etching of plasma on the fiber surface such as roughening, thereby increasing the friction. On the other hand, it is also noticed that, at lower discharge power levels range between 0.10.4 watts and $0.1-0.35$ watts for both air and oxygen plasma, the tensile strength is continuously decreased slightly with exposure time up to 5 minutes which is agreed with the percent increase in weight loss results of treated cotton (as mentioned before). At higher discharge powers the decrease in tensile strength is stopped at 5 minutes of exposure time and increased again whatever the type of plasma used. But it is clearly noticed that, oxygen plasma J. Text. Color. Polym. Sci. 16, No. 2 (2019) treatment is more vigorous in its action compared with air plasma treatment, e.g. at discharge power 1 watts, the increase in tensile strength is reached to $72 \mathrm{~kg} / \mathrm{m}$ with oxygen plasma for treatment time 15 minutes compared to $66 \mathrm{~kg} / \mathrm{m}$ for the same time but at discharge power 2 watts for air plasma.

\section{X-Ray Crystallinity}

Figures $15 \& 16$ and Tables III \& VI show the results of the crystalline size of the treated cotton fabric with air and oxygen plasma respectively. Figure 14 indicates the result of the untreated (control) cotton. It is noticed from the Tables that, when comparing the control with the plasma treated sample, there is no significant change in crystalline size at lower discharge power disregard the type of plasma. While, at higher discharge power, there is a noticeable change and increase in the crystalline size compared with the untreated fabric disregard the plasma type. These changes may be referred to the amorphous structure of cotton, may indicate that plasma only attacks the finishes of available chains on the crystallite surface and amorphous regions, and affected no change in fiber bulk. 
TABLE 1. Tensile strength of untreated and air plasma treated cotton fabric under different conditions of plasma exposure time and discharge power.

\begin{tabular}{|c|c|c|c|c|c|c|c|}
\hline \multirow{2}{*}{$\begin{array}{l}\text { Discharge power } \\
\qquad(\mathrm{w})\end{array}$} & \multicolumn{7}{|c|}{$\begin{array}{l}\text { Tensile Strength values of the untreated and treated cotton fabrics treated for different exposure } \\
\text { times (minutes) }\end{array}$} \\
\hline & 1 & 3 & 5 & 7 & 10 & 12 & 15 \\
\hline untreated & \multicolumn{7}{|c|}{33} \\
\hline 0.1 & 35 & 32 & 25 & 24 & 23 & 22.5 & 20 \\
\hline 0.3 & 41.5 & 40.5 & 35 & 34 & 32 & 31 & 30 \\
\hline 0.4 & 42 & 41.5 & 38 & 37.5 & 38 & 39 & 39 \\
\hline 2 & 43 & 40 & 39 & 45 & 55 & 62 & 66 \\
\hline 5 & 44 & 43 & 41 & 50 & 56 & 65 & 70 \\
\hline 7 & 45 & 44 & 42 & 53 & 60 & 70 & 75 \\
\hline
\end{tabular}

TABLE 2. Tensile strength of untreated and oxygen plasma treated cotton fabric under different conditions of plasma exposure time and discharge power.

\begin{tabular}{|c|c|c|c|c|c|c|c|}
\hline \multirow{2}{*}{$\begin{array}{l}\text { Discharge power } \\
\text { (w) }\end{array}$} & \multicolumn{7}{|c|}{$\begin{array}{l}\text { Tensile Strength values of the untreated and treated cotton fabrics treated for different } \\
\text { exposure times (minutes) }\end{array}$} \\
\hline & 1 & 3 & 5 & 7 & 10 & 12 & 15 \\
\hline untreated & \multicolumn{7}{|c|}{33} \\
\hline 0.1 & 46 & 44 & 42 & 40 & 38 & 35 & 34.5 \\
\hline 0.2 & 48 & 47 & 45 & 42 & 40 & 39 & 39.5 \\
\hline 0.35 & 50 & 48 & 46.5 & 44.5 & 43 & 44 & 45 \\
\hline 1 & 52 & 51.5 & 48 & 51 & 55 & 65 & 72 \\
\hline 6 & 56 & 54 & 50 & 55 & 59 & 68 & 75 \\
\hline 8 & 58 & 56 & 53.5 & 64 & 75 & 81 & 84 \\
\hline
\end{tabular}

TABLE 3. Crystallite size (Á) of cotton samples treated with air plasma under atmospheric pressure at 5 minutes exposure time of treatment for different discharge power.

\begin{tabular}{|c|c|}
\hline Discharge power (watt) & Crystallite size (文) \\
\hline 0 & 2.276 \\
\hline 0.1 & 2.305 \\
\hline 0.3 & 2.308 \\
\hline 5 & 5.364 \\
\hline 7 & 7.073 \\
\hline
\end{tabular}

TABLE 4. Crystallite size (Á) of cotton samples treated with oxygen plasma under atmospheric pressure at 5 minutes exposure time of treatment for different discharge power.

\begin{tabular}{|c|c|}
\hline Discharge power (watt) & Crystallite size (Á) \\
\hline 0 & 2.276 \\
\hline 0.1 & 2.290 \\
\hline 0.2 & 2.491 \\
\hline 6 & 6.3436 \\
\hline 8 & 8.3806 \\
\hline
\end{tabular}




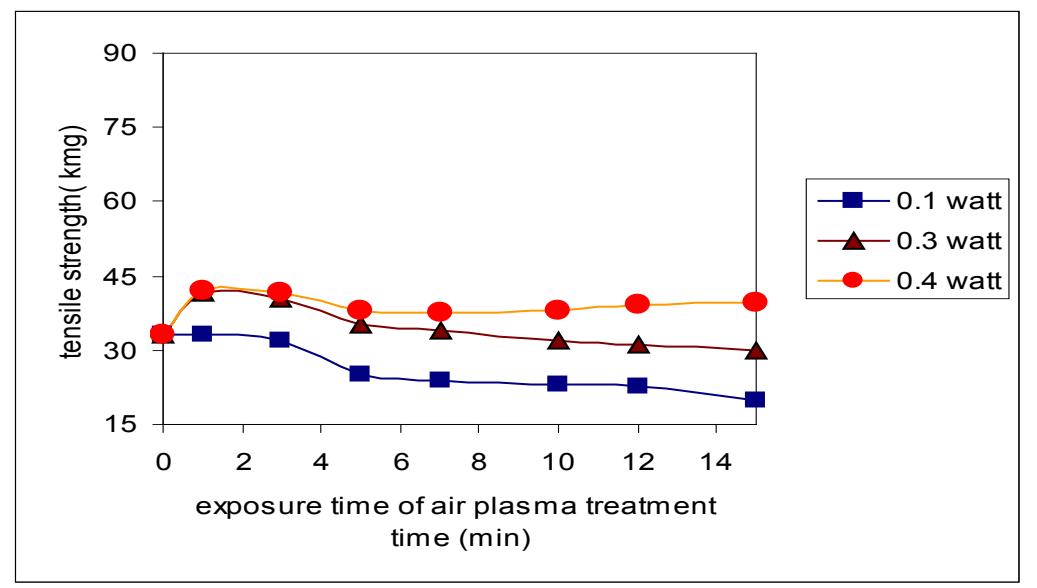

Fig. 10. Tensile strength of air plasma treated cotton fabric under atmospheric pressure for different exposure time at discharge power $0.1,0.3,0.4$ watt.

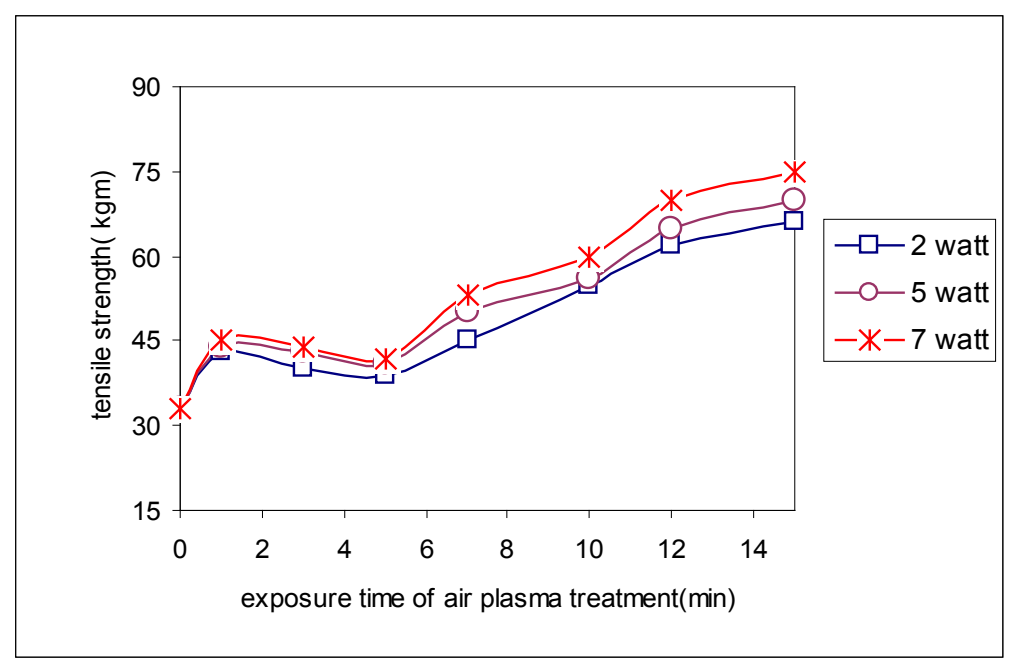

Fig. 11. Tensile strength of air plasma treated cotton fabric under atmospheric pressure for different exposure time at discharge power $2,5,7$ watt.

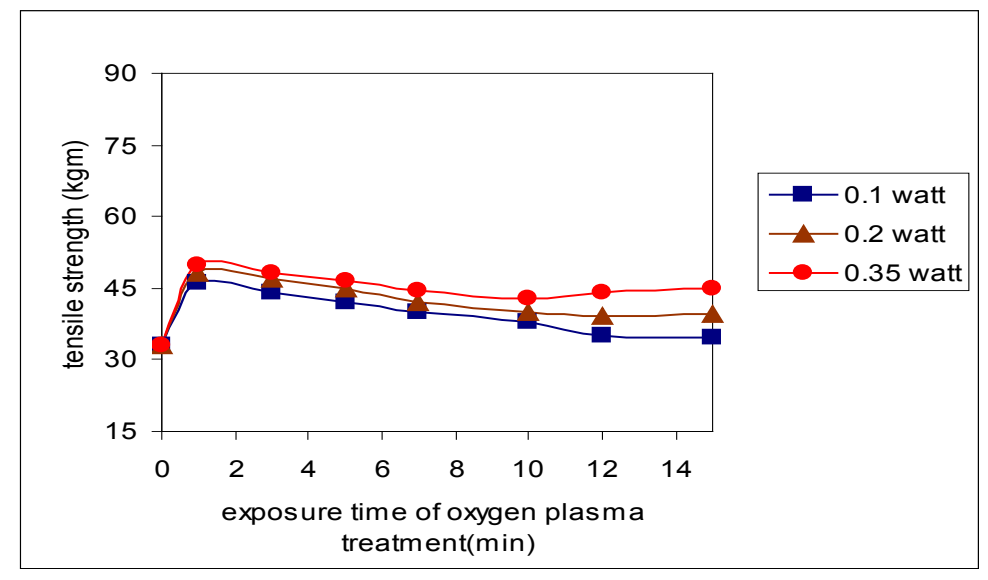

Fig. 12. Tensile strength of oxygen plasma treated cotton fabric under atmospheric pressure for different exposure time at discharge power $0.1,0.2,0.35$ watt.

J. Text. Color. Polym. Sci. 16, No. 2 (2019) 


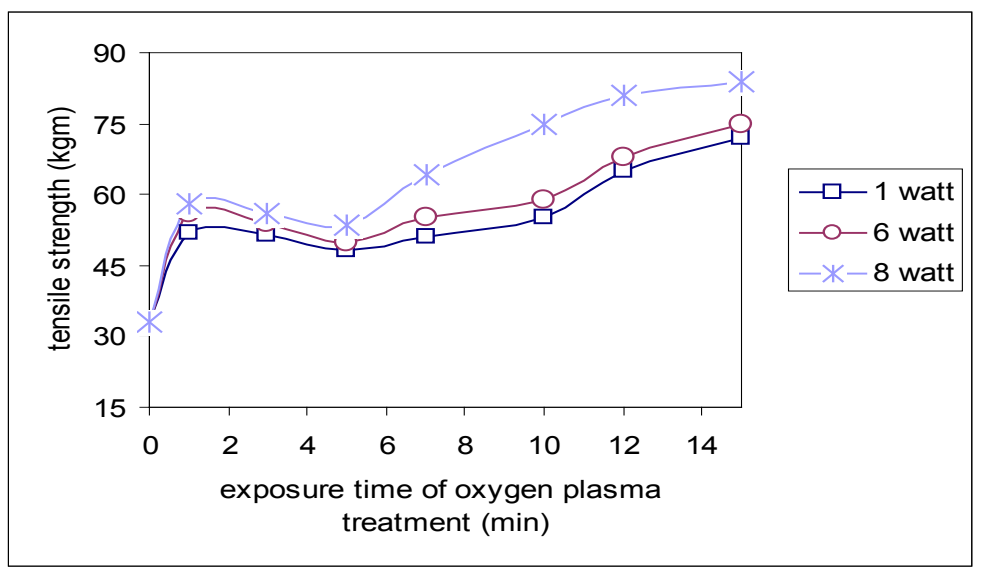

Fig. 13. Tensile strength of oxygen plasma treated cotton fabric under atmospheric pressure for different exposure time at discharge power $1,6,8$ watt.

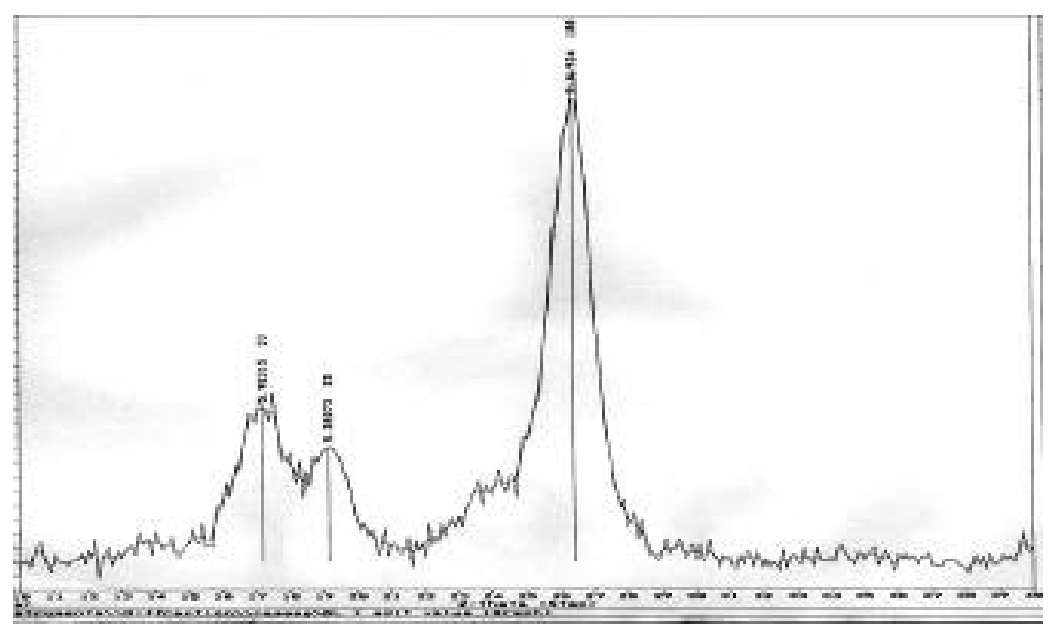

Fig. 14. Crystallite size (Á) of untreated cotton fabric.
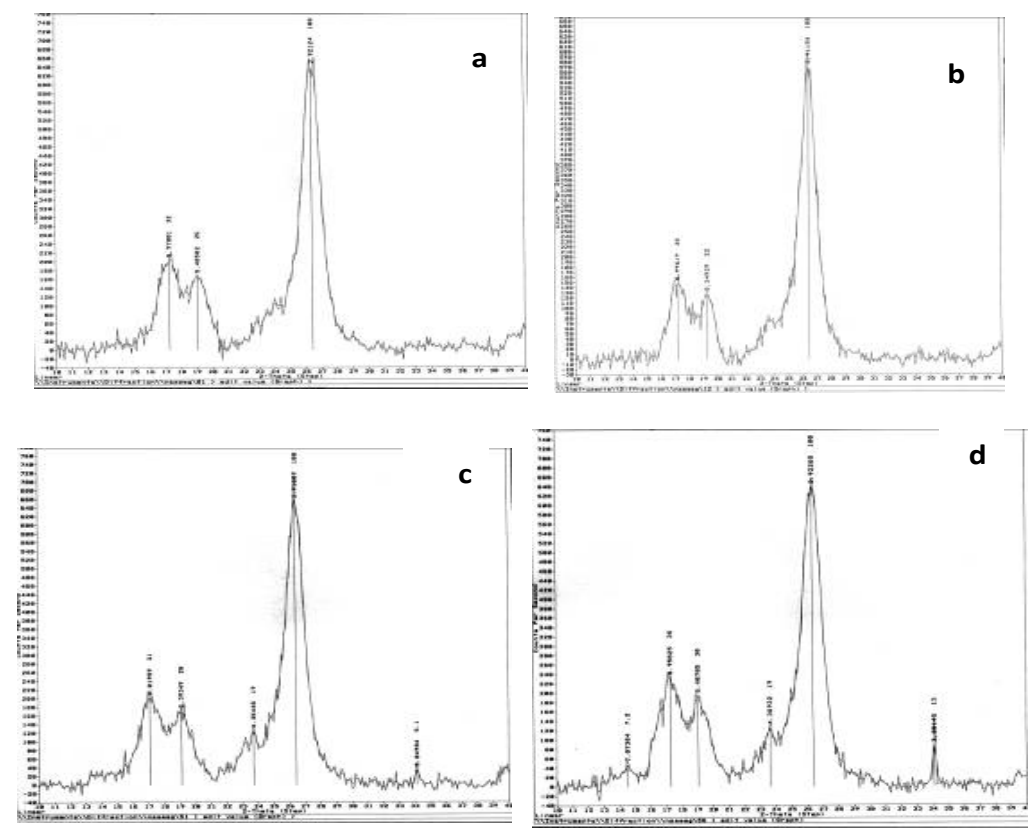

Fig. 15. X-ray diffraction patterns of cotton fabric treated with air plasma at 5 minutes for different discharge powers. (a) 0.1 watts (b) 0.3 watts (c) 5 watts (d) 7 watts 

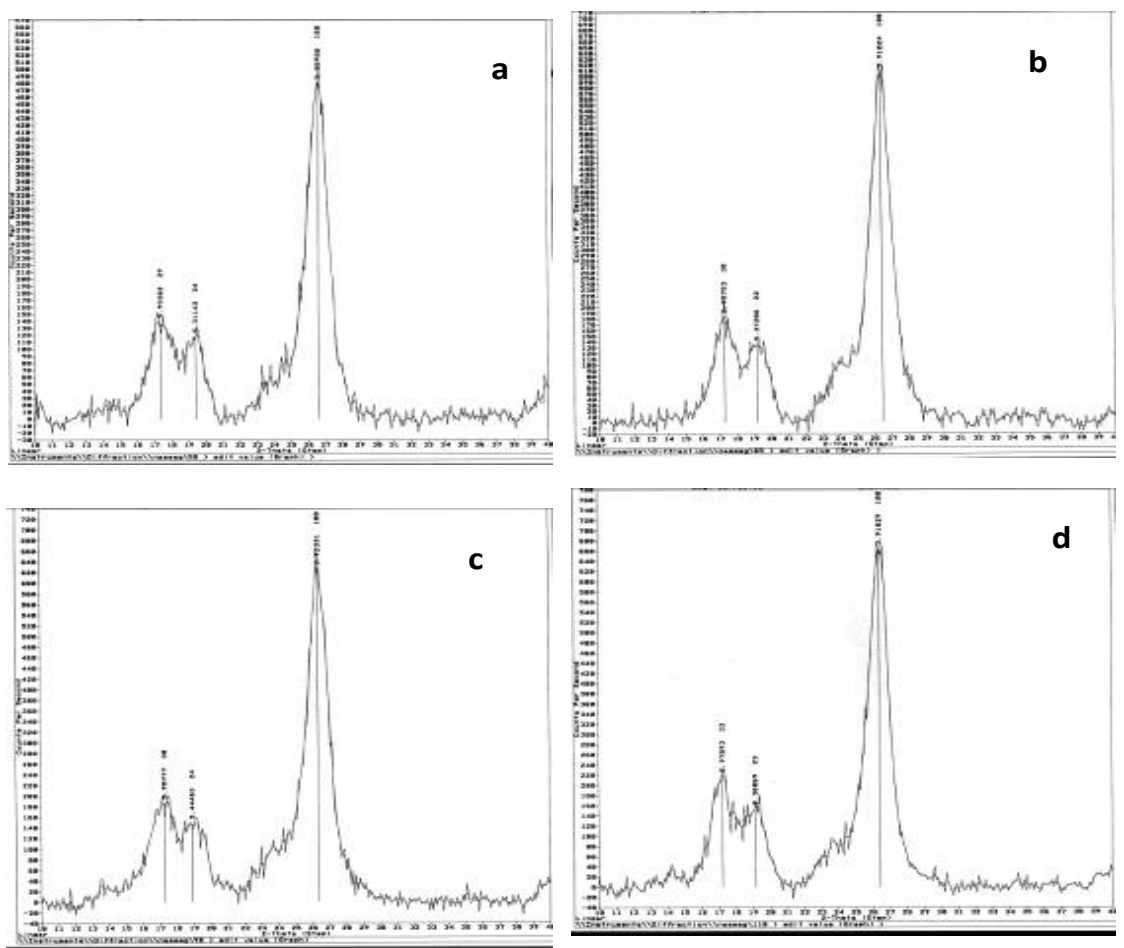

Fig.16. X-ray diffraction patterns of cotton fabric treated with oxygen plasma at 5 minutes for different discharge powers. (a) 0.1 watts (b) 0.2 watts (c) 6 watts

(d) 8 watts

Scanning Electron Microscope (SEM)

Figures 18\& 19 show SEM micrographs of samples treated with air and oxygen plasma respectively, illustrating a progressive change in the fiber surface morphology with treatment time. The untreated cotton fabric (Figure 17) showed a relatively smooth surface with some groves (presumably on artifact of the fiber production process). The change of the fabric surface area may be due to the surface erosion of the cotton fiber during plasma treatment, as well as, the etching effect of the plasma treatment on the fiber which damages the fiber surface. Etching is very clear during plasma treatment regardless the time of treatment and level of discharge power. The damage appears either as surface cracks or as protruding or peeled off fragments on the fiber surface. Such surface damage to the primary wall of the cotton fibers, coupled with the introduction of more polar chemical groups could render fibers more hydrophilic and accessible of dyes, there by increasing the color strength. In other studies, plasma-treated cotton fibers show evidence of physical surface damage that leads to a greater attraction for water or even oil. This physical damage caused by plasma treatment appears to increase fiber wettability (as mentioned before).

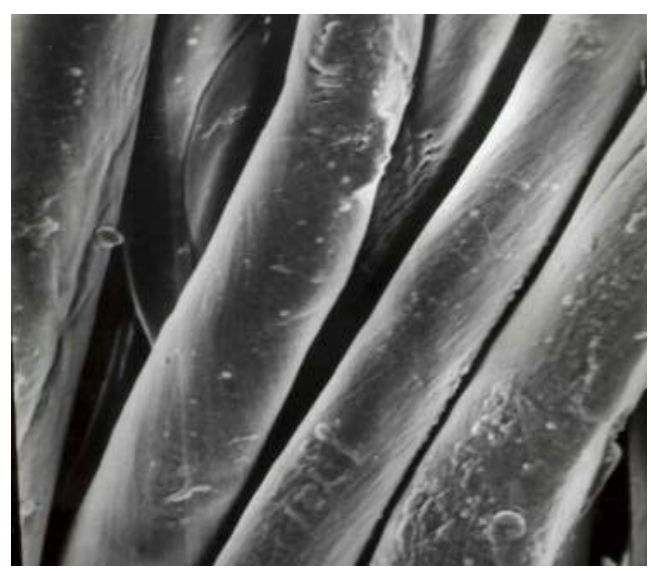

Fig. 17. SEM of untreated cotton fabric $(1500 \mathrm{x})$. 

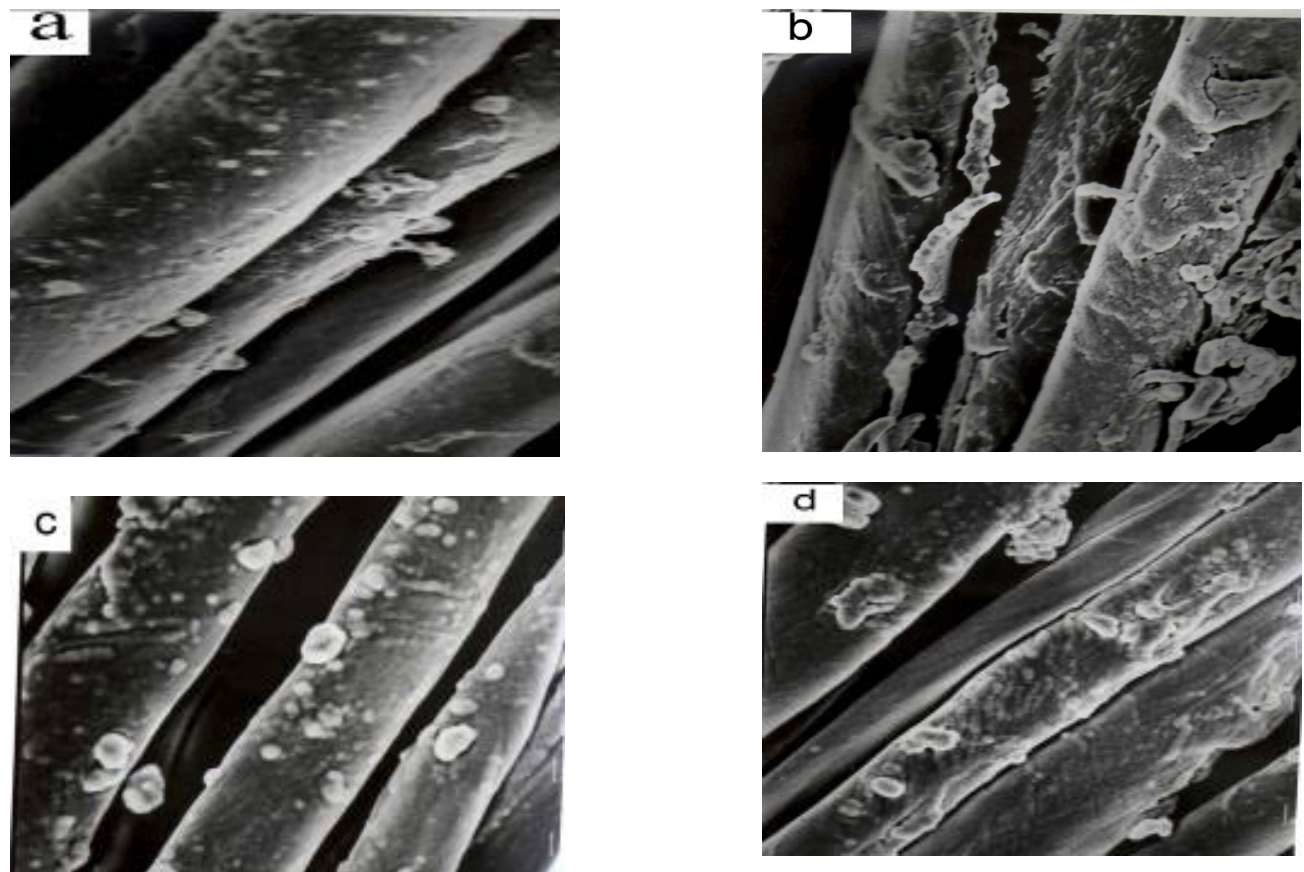

Fig.18. SEM of cotton fabric treated with air plasma at different conditions (a) 0.3 watt -1 min (b) 0.3 watt -15 $\min (c) 0.34$ watt -1 min. (d) 0.34 watt -15 min (1500 x).
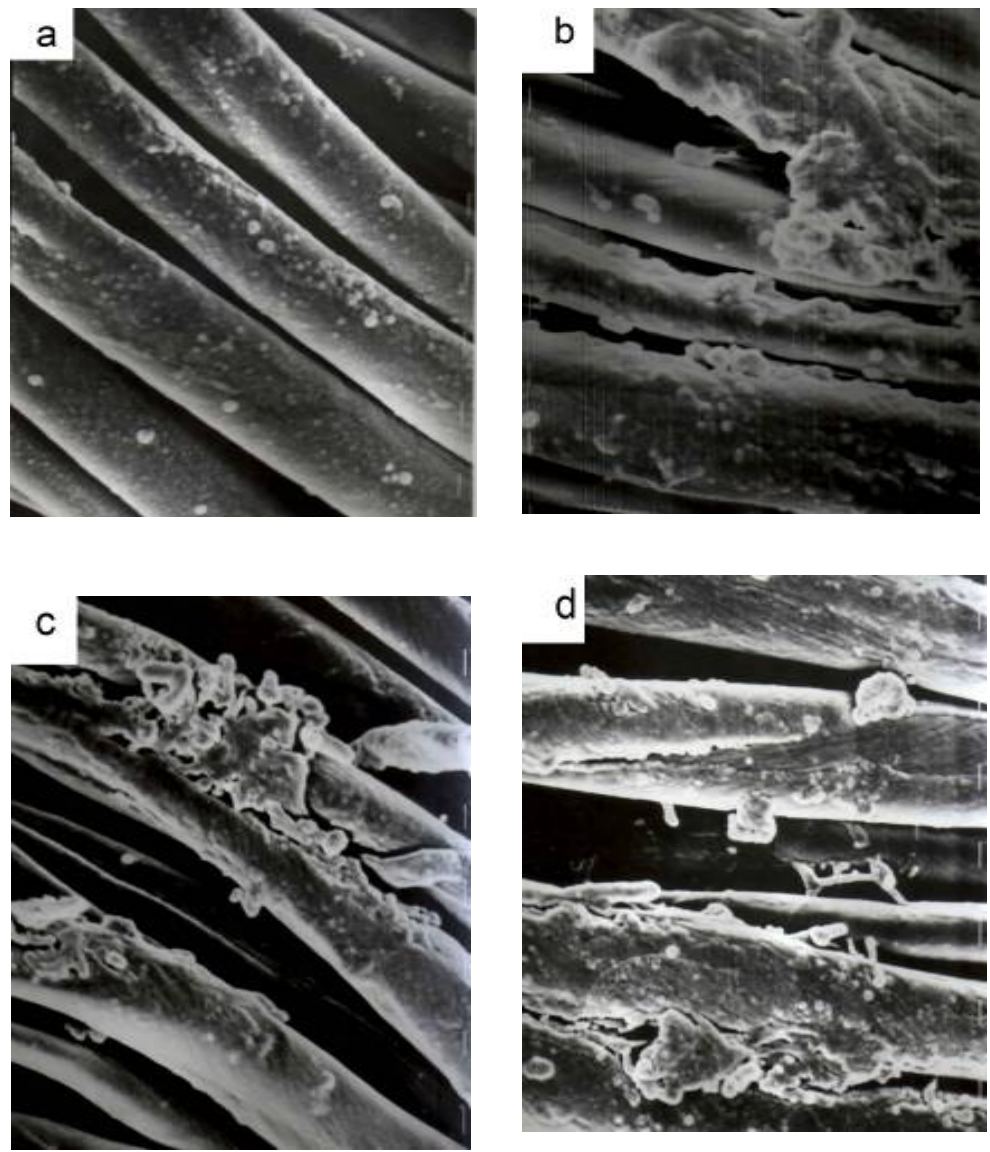

Fig. 19. SEM of cotton fabric treated with oxygen plasma at different conditions (a) 0.3 watt -1 min (b) 0.3 watt 15 min (c) 0.34 watt -1 min. (d) 0.34 watt -15 min (1500x). 
Fourier Transition Infrared Spectroscopy (FTIR)

The infrared spectrum of untreated polyester fabric is shown by Figure 20. The IR spectrums of the samples treated by air and oxygen plasma under atmospheric pressure are cleared by Figures 21 and 22 respectively. The plasma treatment is carried out for different intervals of time at various levels of discharge power. The relative intensities of selected bands in the FTIR spectra of polyester samples treated with air and oxygen plasma are represented in Tables V\&VI respectively. It is well known that plasma treatment is effective in modifying fiber surfaces, carrying out some composition changes and improving hydrophilic properties by inducing polar functional groups such as $-\mathrm{CO}-,-\mathrm{C}=\mathrm{O},-\mathrm{COOH}$ The sharp bands located at $3430.5 \mathrm{Cm}^{-1}, 2363.1 \mathrm{Cm}^{-1}$ and $1680-$ $1780 \mathrm{Cm}^{-1}$ and $2900 \mathrm{Cm}^{-1}$ are due to the streching mode of free hydroxyl (v́ $\mathrm{O}-\mathrm{H})$, cyanide (v́ $\mathrm{C} \equiv \mathrm{N})$, carbonly $(v \mathrm{C}=\mathrm{O}$ ) and carbon hydrogen bond (v $\mathrm{C}-\mathrm{H}$ ) respectively. The decrease in their intensities (TablesV\&VI) means increasing in their number on the fiber surface. Plasma treatment in air or oxygen leads to oxidation of the cellulose chain molecules in cotton. The cellulosic $\mathrm{O}-\mathrm{H}$ groups are oxidized to carbonyl and carboxyl groups replacing some of the cellulose $\mathrm{O}-\mathrm{H}$ groups in the fiber chain molecules by carbonyl or carboxyl groups will disrupt the hydrogenbonding network within the fiber. This would make the cotton fibers more accessible to water molecules which should, in turn, promote greater swelling of cotton fibers. This theory is supported by the work of Rabinov et.al which suggested that an increase in the amount of $-\mathrm{COOH}$ groups on cotton bring about an increase in the amount of water of swelling.

The effects indication that The components of $\mathrm{COOH}$ and $\mathrm{CH}$ significantly increase the fiber surface after being treated with no oxygen or air. The increase of the oxidative component of oxygen plasma is slightly larger than that of air plasma. The results are consistent with previous findings of low temperature plasma treatment of cotton fibers. The increase of the oxidation and $\mathrm{CH}$ components can be explained by increasing the density of free radicals and fractures of the glucoside bond to form activated carbonyls on the surface of the fibers, respectively.

TABLE 5. FTIR of untreated and air plasma treated cotton fabric for 5 mins exposure time at different discharge power.

\begin{tabular}{|c|c|c|c|c|}
\hline \multirow{2}{*}{$\begin{array}{l}\text { Discharge } \\
\text { Power } \\
\text { (W) }\end{array}$} & \multicolumn{4}{|c|}{$\begin{array}{l}\text { Relative intensities of selected bands in the FTIR spectra of cotton samples treated with } \\
\text { air plasma for } 5 \text { mins., }\end{array}$} \\
\hline & (v́O-H) & (v́ $\mathbf{C} \equiv \mathbf{N})$ & (v́ $\mathbf{C}=\mathbf{O}$ ) & (v́ C-H) \\
\hline 0 & 0.650 & 0.049 & 0.186 & 0.249 \\
\hline 0.1 & 0.615 & 0.045 & 0.158 & 0.20 \\
\hline 0.3 & 0.545 & 0.032 & 0.134 & 0.193 \\
\hline 0.4 & 0.538 & 0.033 & 0.125 & 0.182 \\
\hline 2 & 0.523 & 0.031 & 0.122 & 0.174 \\
\hline 5 & 0.406 & 0.030 & 0.120 & 0.161 \\
\hline 7 & 0.401 & 0.029 & 0.119 & 0.160 \\
\hline
\end{tabular}

TABLE 6. FTIR of untreated and oxygen plasma treated cotton fabric for 5 mins exposure time at different discharge power.

\begin{tabular}{|c|c|c|c|c|}
\hline \multirow{2}{*}{$\begin{array}{c}\text { Discharge } \\
\text { Power } \\
\text { (W) }\end{array}$} & \multicolumn{4}{|c|}{$\begin{array}{l}\text { Relative intensities of selected bands in the FTIR spectra of cotton samples treated with } \\
\text { oxygen plasma for } 5 \text { mins., }\end{array}$} \\
\hline & $($ (vO-H) & (v́ $\mathbf{C} \equiv \mathbf{N})$ & (v́ $\mathbf{C}=\mathbf{O}$ ) & $(\mathbf{v} \mathbf{C}-\mathbf{H})$ \\
\hline 0 & 0.650 & 0.049 & 0.186 & 0.249 \\
\hline 0.1 & 0.569 & 0.038 & 0.142 & 0.20 \\
\hline 0.2 & 0.561 & 0.032 & 0.140 & 0.20 \\
\hline 0.35 & 0.446 & 0.031 & 0.111 & 0.18 \\
\hline 1 & 0.442 & 0.030 & 0.109 & 0.16 \\
\hline 6 & 0.438 & 0.029 & 0.105 & 0.14 \\
\hline 8 & 0.430 & 0.027 & 0.102 & 0.12 \\
\hline
\end{tabular}

J. Text. Color. Polym. Sci. 16, No. 2 (2019) 


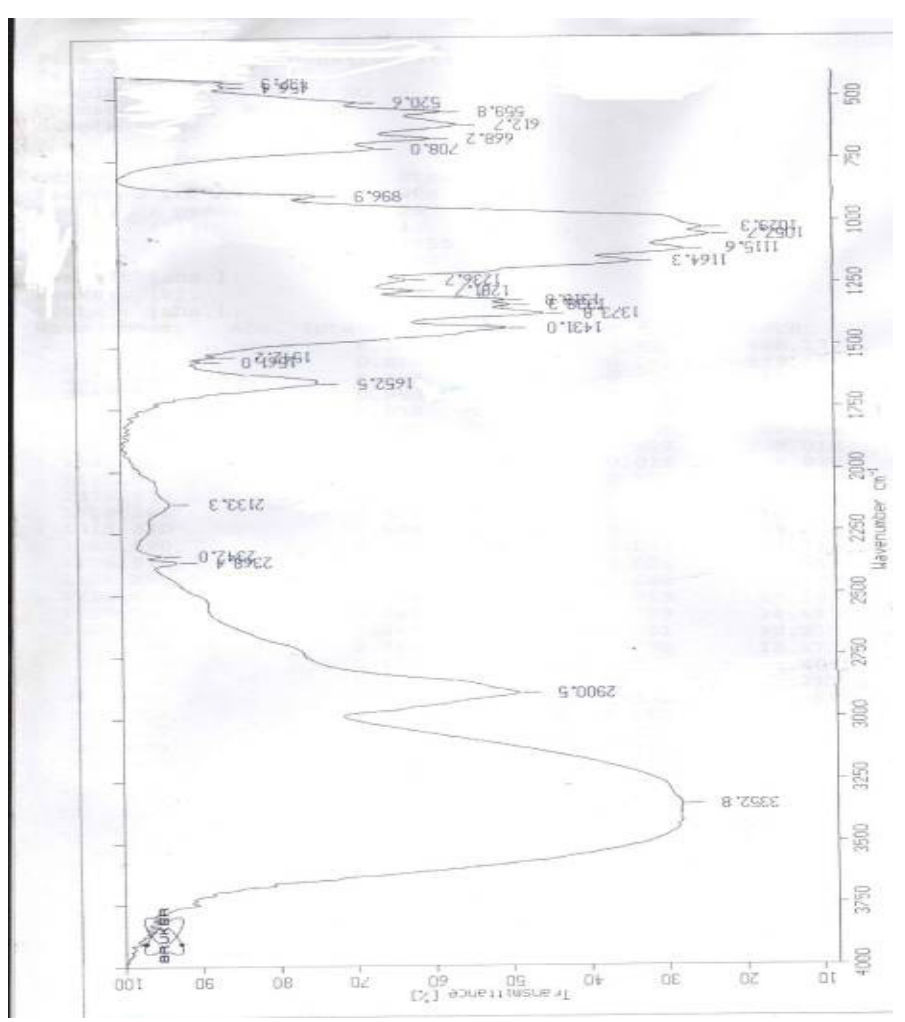

Fig. 20. FTIR of untreated cotton fabric

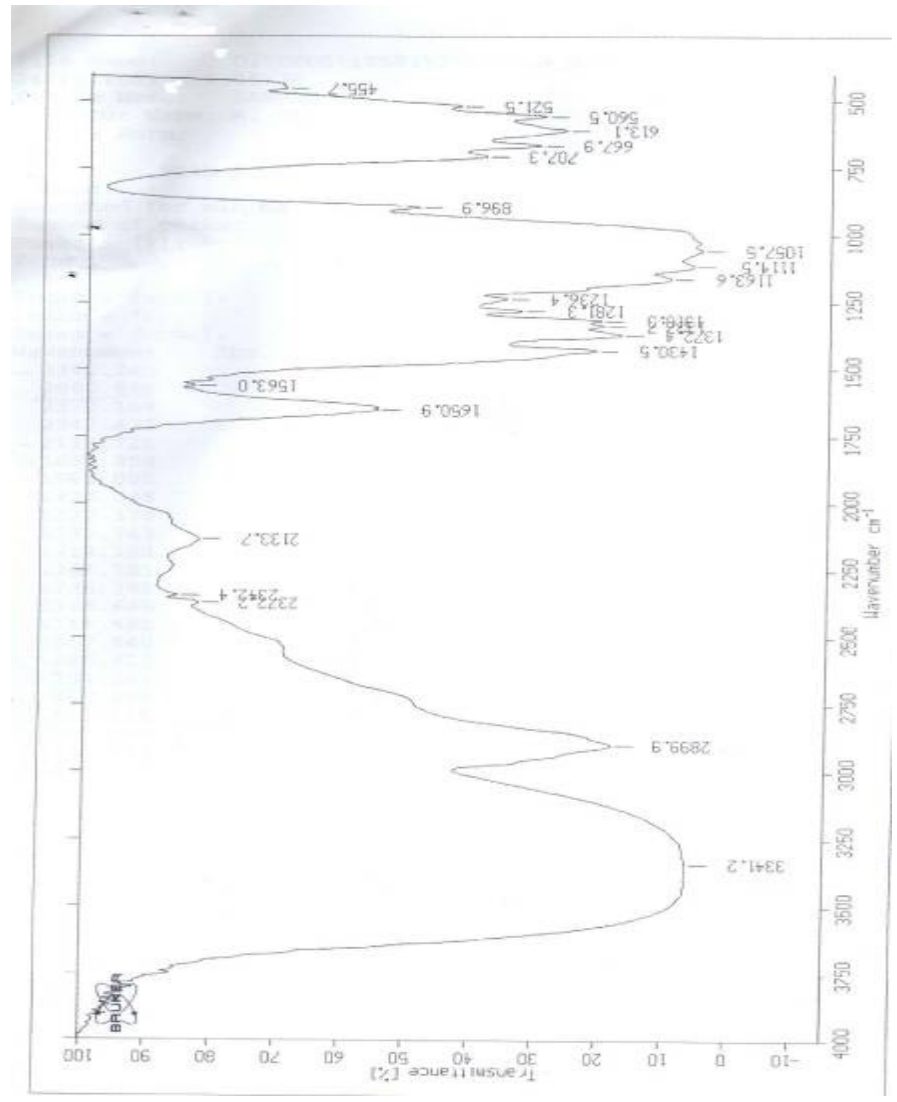

Fig. 21.a. FTIR of air plasma treated cotton fabric at 0.1 watt\& 5 min.

J. Text. Color. Polym. Sci. 16, No. 2 (2019) 


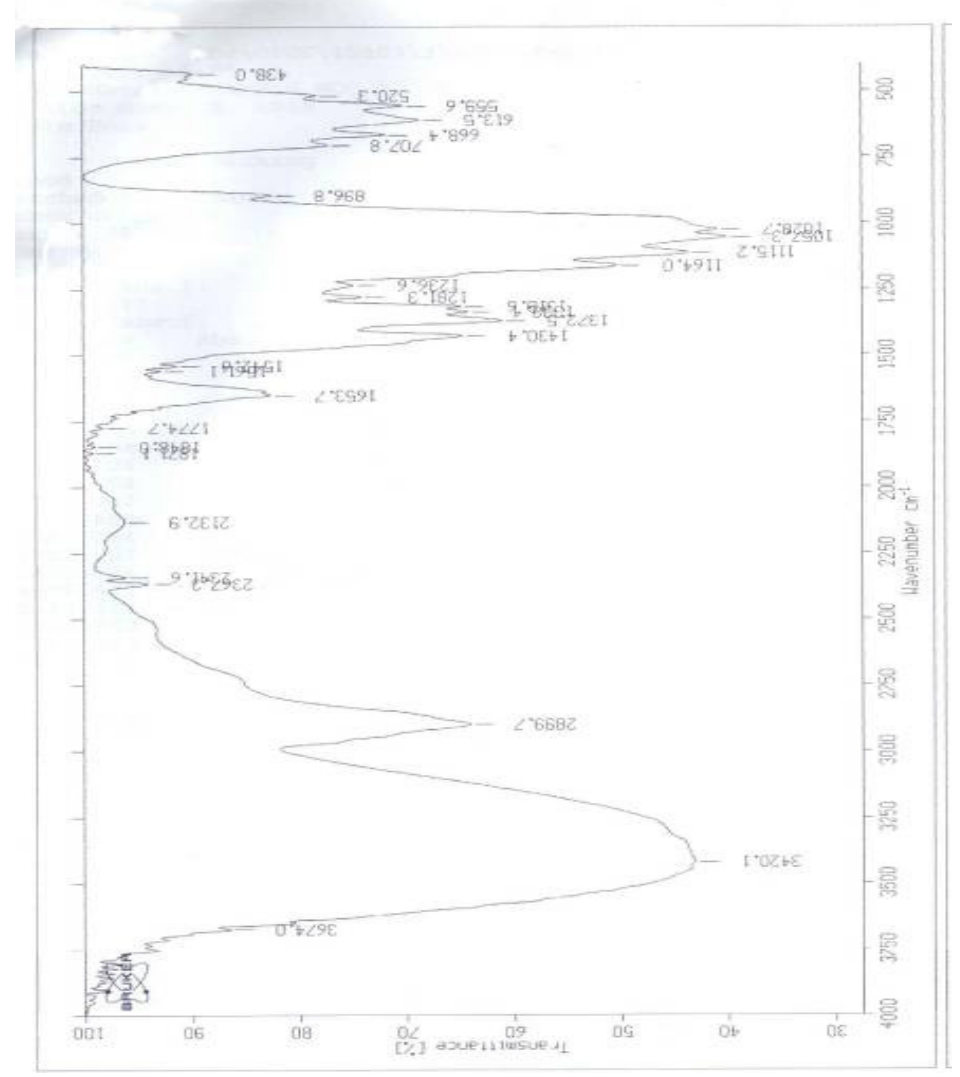

Fig. 21.b. FTIR of air plasma treated cotton fabric at 0.3 watt\& 5 min.

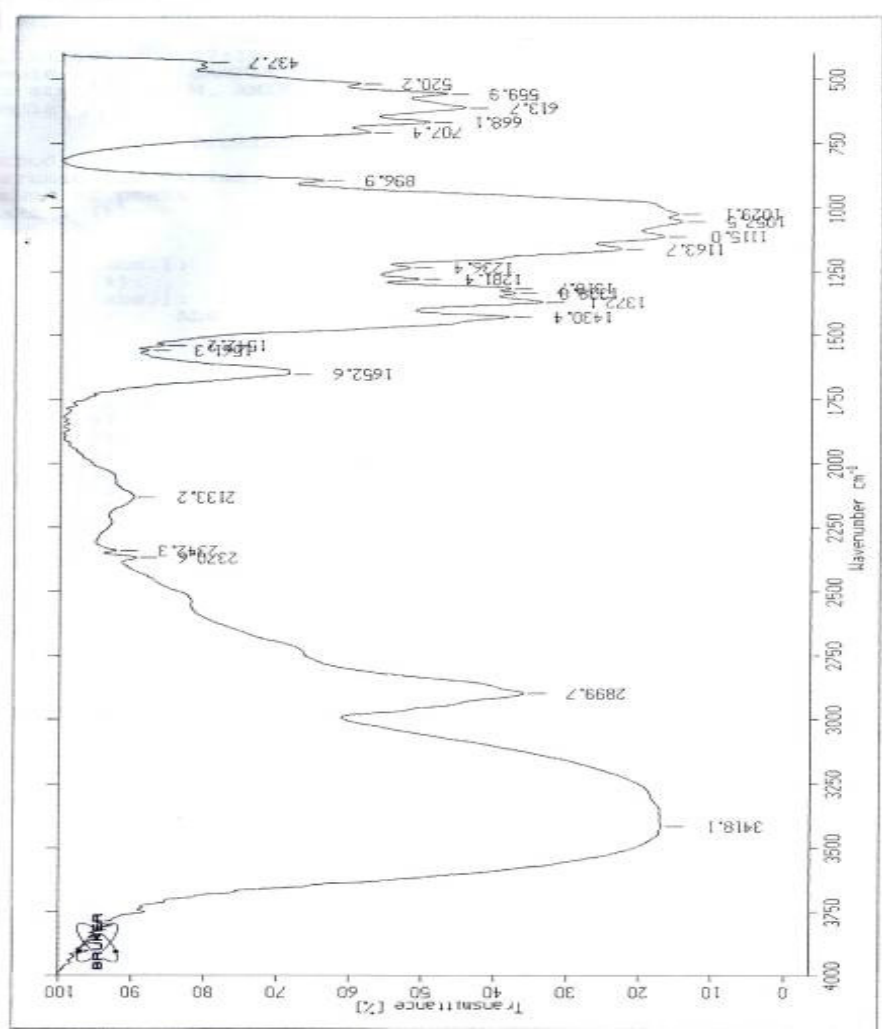

Fig. 21.c. FTIR of air plasma treated cotton fabric at 5 watt\& 5 min.

J. Text. Color. Polym. Sci. 16, No. 2 (2019) 


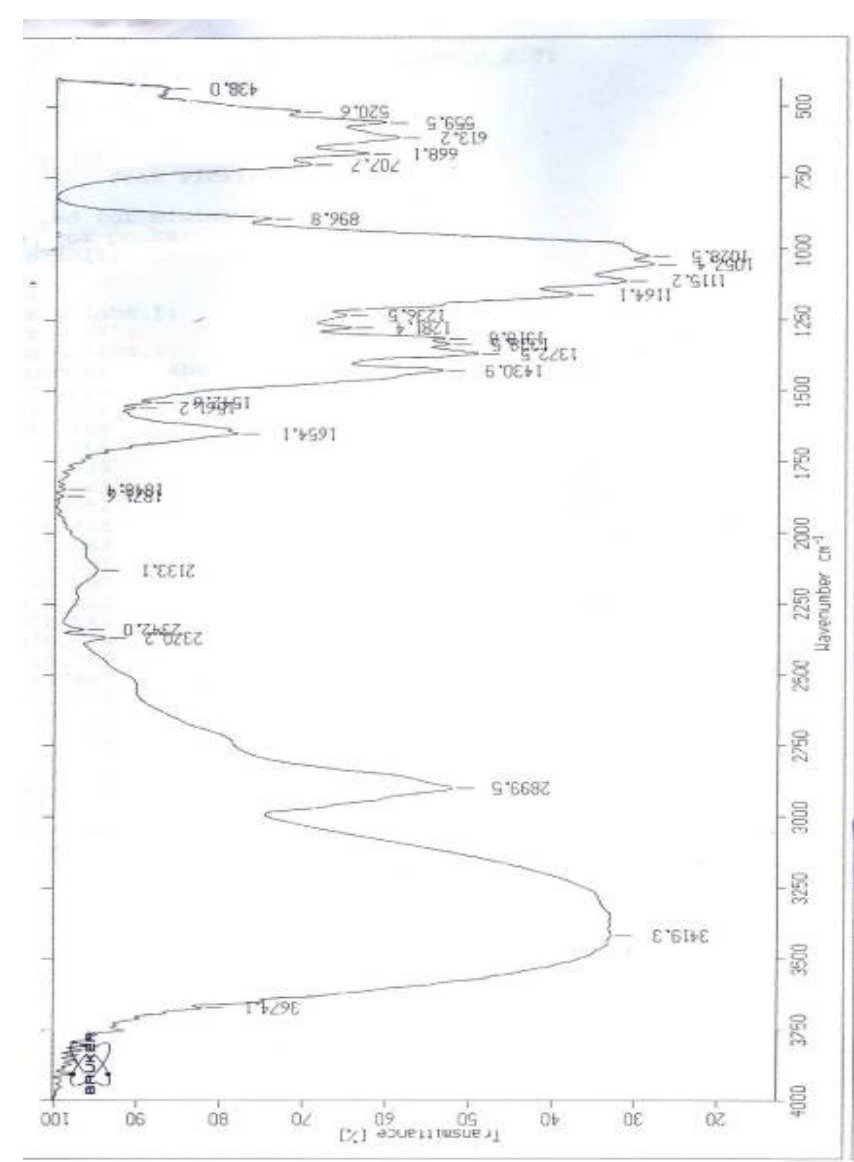

Fig. 21.d. FTIR of air plasma treated cotton fabric at 7 watt\& 5 min.

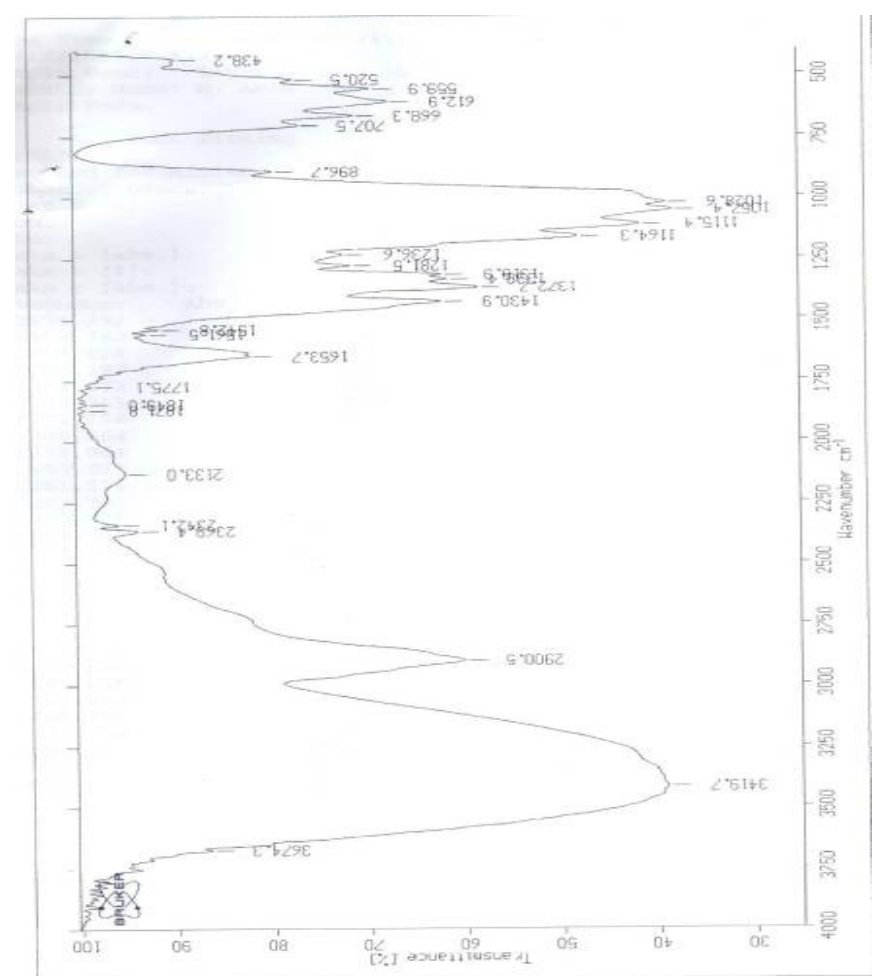

Fig. 22.a. FTIR of oxygen plasma treated cotton fabric at 0.1 watt\& 5 min.

J. Text. Color. Polym. Sci. 16, No. 2 (2019) 


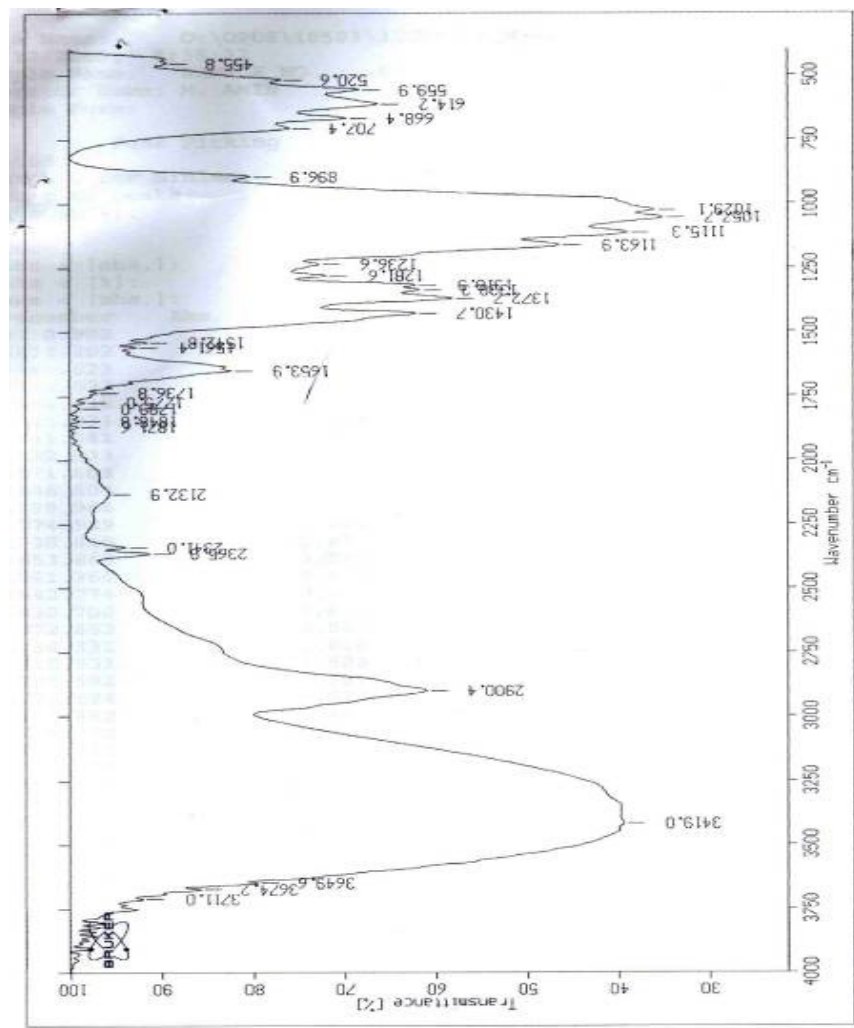

Fig. 22.b. FTIR of oxygen plasma treated cotton fabric at 0.2 watt\& $5 \mathrm{~min}$.

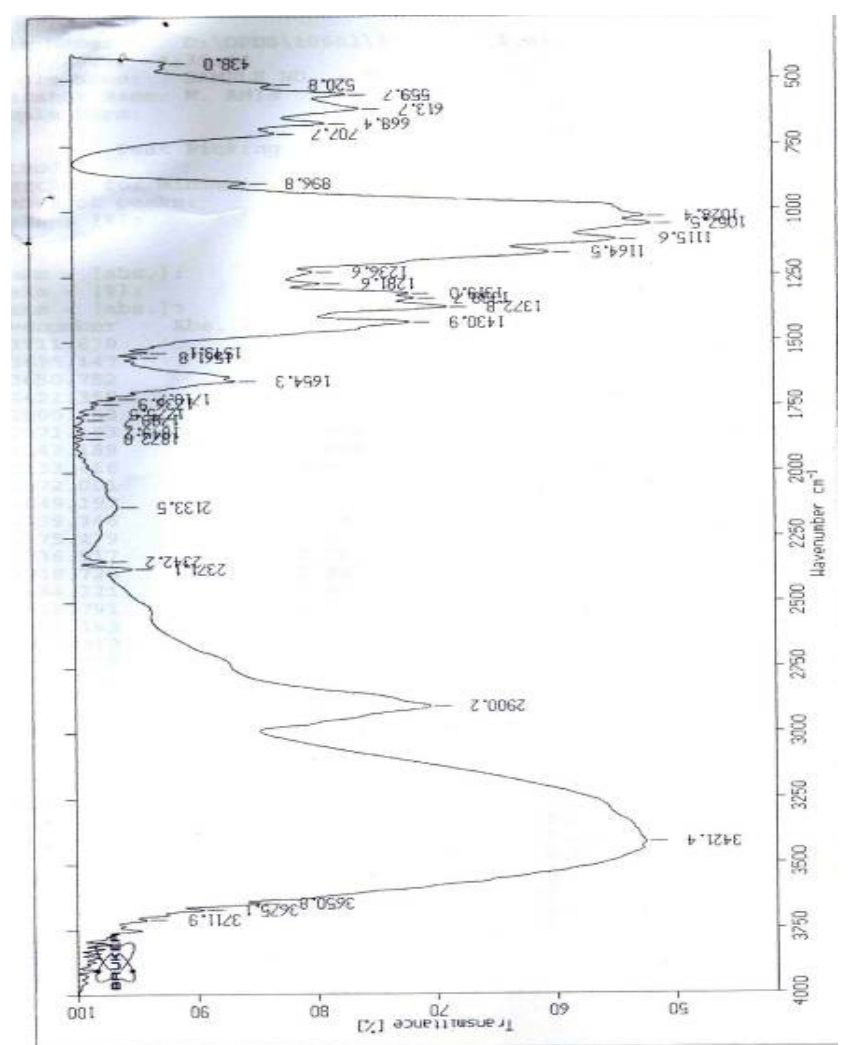

Fig. 22.c. FTIR of oxygen plasma treated cotton fabric at 6 watt\& 5 min. 


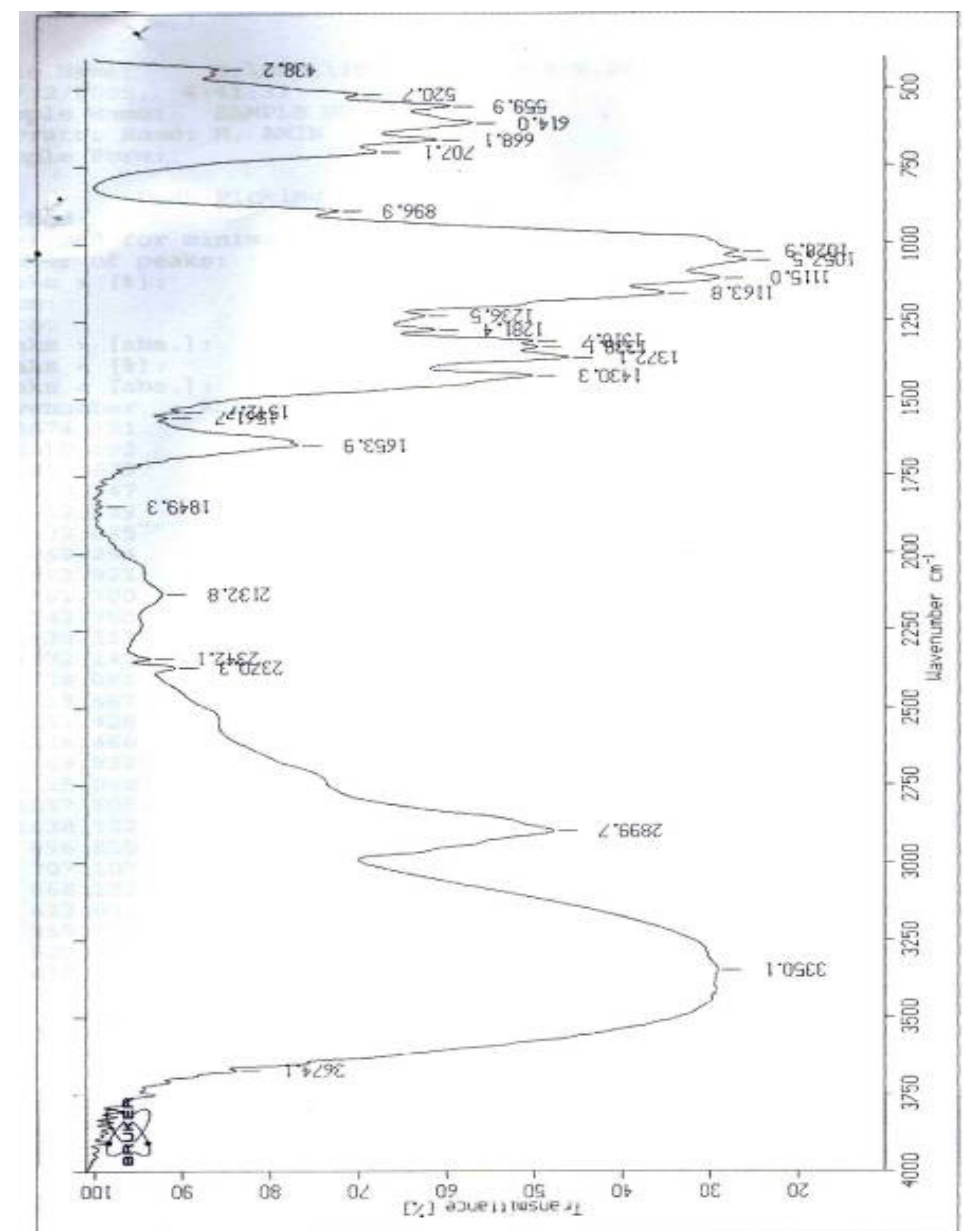

Fig. 22. d. FTIR of oxygen plasma treated cotton fabric at 8 watt\& 5 min.

\section{Color assessment}

The effect of plasma treatment time on the color strength of printed treated cotton in two different gas atmospheres (air and oxygen) for different discharge power was studied. The color strength results obtained were plotted in Figures 23, 24 and 25,26 respectively. The effect of plasma treatment in both air and oxygen appears to increase the color strength of cotton fabric. Oxygen plasma treatment is more effective than air plasma treatment on the surface etching of cotton. Discharge power plays an important role and affect the results to a large extent. At low powers for both air and oxygen plasma as shown in Figures 23\&24, the color strength of the printed treated cotton samples increases as the treatment time increases up to about 5 minutes, then it becomes nearly constant. As we noticed that oxygen plasma treatment is more effective as mentioned before, e.g., the color strength results obtained by air plasma at power 0.3 watts ranges between 119.4-125.5 for treatment time 1-15 minutes. While, it ranges between $120.7-127.4$ at discharge power 0.2 watts when using oxygen plasma for the same treatment time. This shows that the increase in color strength depends more on the oxygen component of the air than on the nitrogen component, which supports an oxidative mechanism of attack of cotton. At higher discharge power ranges between 2-7 watts and 1-8 watts for air and oxygen plasmas respectively, the same trend holds true, but at 5 minutes of plasma treatment time, the color strength decreases. Generally speaking, possible contributory factors leading to the increase in color strength for air and oxygen plasma treated cotton are considered to be: - The chemical changes in the cotton fiber surface due to the oxidative attack on the cellulose, leading to the formation of carbonyl and carboxyl groups in the fiber

- The possibility of the formation of free radicals on the cellulosic chains of cotton through in oxygen or air plasma treatment.

The decrease in color strength results obtained the increased crystalline phase is simple reflected in the decrease in the dyeable amorphous phase. 


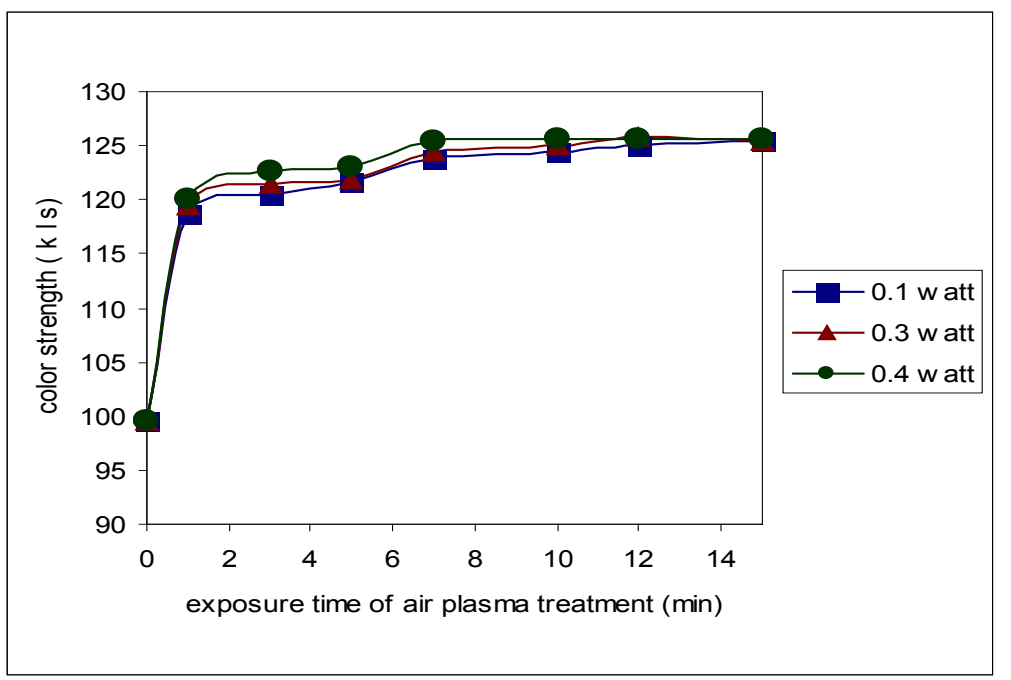

Fig. 23. Color strength $(\mathrm{K} / \mathrm{S})$ of printed cotton fabric treated with air plasma under atmospheric pressure at discharge power $0.1,0.3,0.4$ watts.

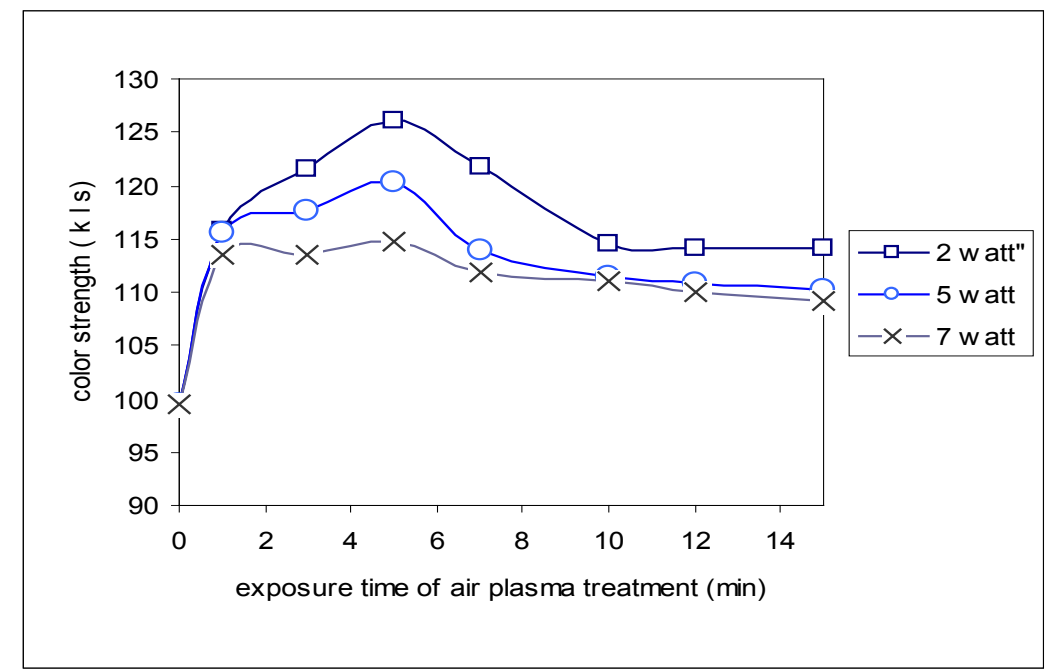

Fig. 24. Color strength $(\mathrm{K} / \mathrm{S})$ of printed cotton fabric treated with air plasma under atmospheric pressure at discharge power $2,5,7$ watts.

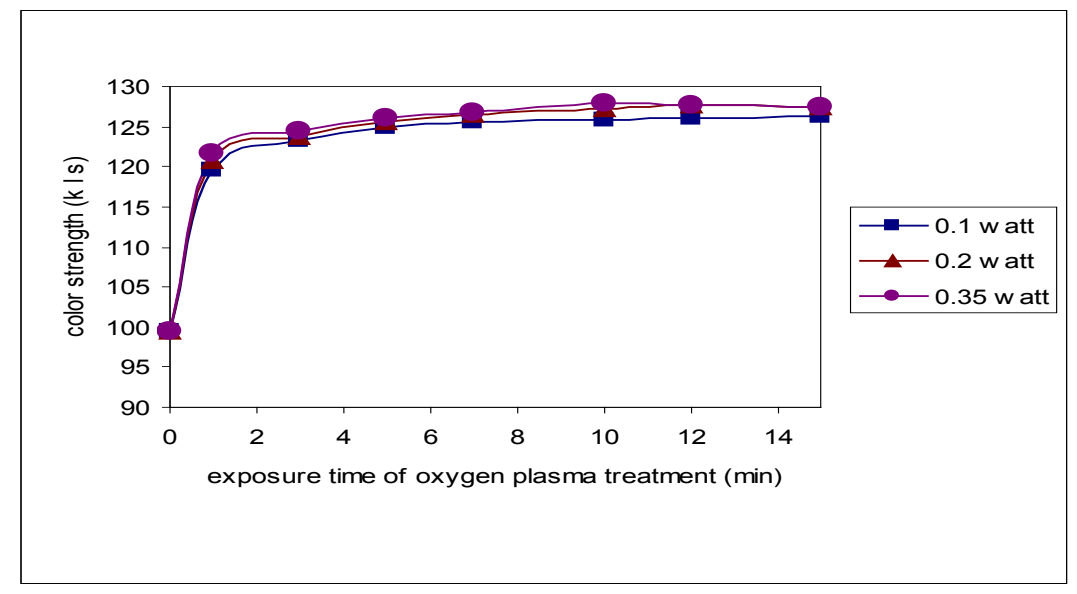

Fig. 25. Color Strength (K/S) of printed PET fabric treated with oxygen plasma under atmospheric pressure at discharge power0.1, $0.2,0.35$ watts.

J. Text. Color. Polym. Sci. 16, No. 2 (2019) 


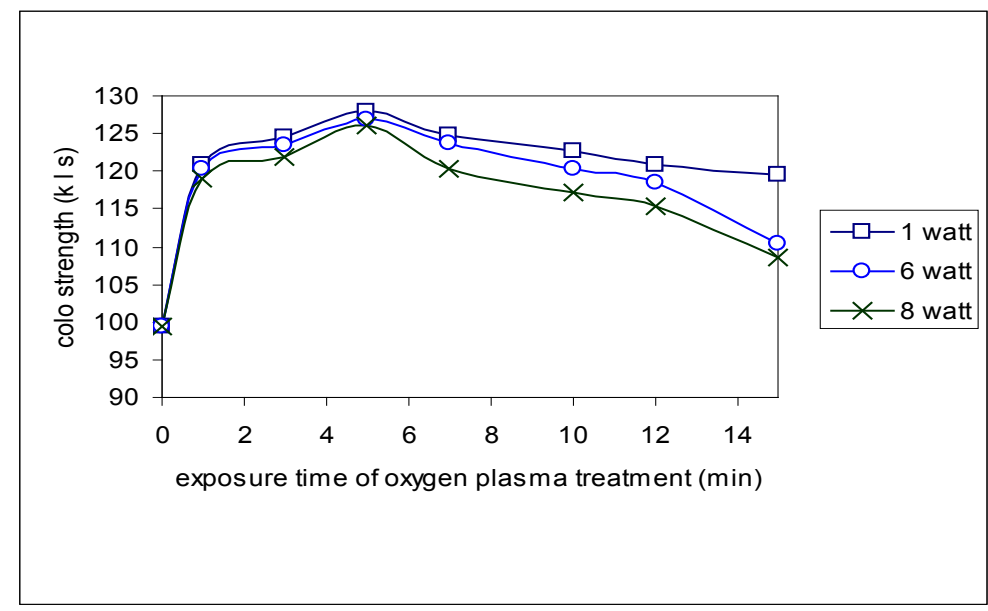

Fig. 26. Color Strength $(\mathrm{K} / \mathrm{S})$ of printed PET fabric treated with oxygen plasma under atmospheric pressure at discharge power $1,6,8$ watts.

\section{Handle}

Table VII\&VIII show the effect of air and oxygen plasma exposure time on the roughness of treated printed cotton fabric respectively at different levels of discharge power. The roughness measured for the untreated cotton sample is 13.96. It is clear that, there is an improvement in the roughness values obtained for the treated printed cotton samples compared with the untreated ones. The treated samples became softer after exposure to plasma treatment regardless of the plasma conditions (time, power, gas type) for both air and oxygen plasma.

\section{Fastness Properties}

From visual observation, it was noted that all the fabric samples which have been printed are bright and level. Tables X \& XI indicate the results obtained in washing, rubbing and perspiration fastness for untreated and treated cotton fabric prints with either air or oxygen plasma respectively. The comparison of the untreated versus treated samples demonstrates that the ratings of perspiration (acidic \& alkaline) and wash fastness for all the samples are nearly similar. ]

TABLE 7. Roughness for untreated and air plasma treated cotton fabrics under different conditions of exposure time and discharge power.

\begin{tabular}{|c|c|c|c|c|c|c|}
\hline $\begin{array}{c}\text { Discharge power } \\
(\mathbf{w})\end{array}$ & \multicolumn{6}{|l}{$\begin{array}{l}\text { Roughness values of the untreated and plasma treated cotton fabrics for different exposure } \\
\text { times(minutes) }\end{array}$} \\
\cline { 2 - 7 } & 1 & 3 & 5 & 10 & 12 & 15 \\
\hline untreated & \multicolumn{7}{|c|}{13.96} \\
\hline 0.1 & 13.35 & 13.16 & 13.03 & 12.95 & 12.53 & 12.34 \\
\hline 0.3 & 13.33 & 13.11 & 12.99 & 12.75 & 12.45 & 12.45 \\
\hline 0.4 & 13.23 & 13.09 & 12.55 & 12.01 & 12.05 & 12.12 \\
\hline 2 & 13.13 & 12.65 & 12.32 & 12.33 & 12.35 & 12.4 \\
\hline 5 & 12.89 & 11.98 & 11.33 & 11.34 & 11.4 & 11.4 \\
\hline 7 & 11.24 & 11.12 & 10.23 & 10.35 & 10.37 & 10.42 \\
\hline
\end{tabular}

TABLE 8. Roughness for untreated and oxygen plasma treated cotton fabrics under different conditions of exposure time and discharge power.

\begin{tabular}{|c|c|c|c|c|c|c|}
\hline \multirow{2}{*}{$\begin{array}{l}\text { Discharge power } \\
\qquad(\mathbf{w})\end{array}$} & \multicolumn{6}{|c|}{$\begin{array}{l}\text { Roughness values of the untreated and plasma treated cotton fabrics for different exposure } \\
\text { times (minutes) }\end{array}$} \\
\hline & 1 & 3 & 5 & 10 & 12 & 15 \\
\hline untreated & \multicolumn{6}{|c|}{13.96} \\
\hline 0.1 & 13.27 & 13.18 & 12.97 & 12.65 & 12.54 & 12.34 \\
\hline 0.2 & 13.15 & 13.06 & 12.79 & 12.50 & 12.23 & 12.25 \\
\hline 0.35 & 13.09 & 12.89 & 12.55 & 12.14 & 12.15 & 12.5 \\
\hline 1 & 12.87 & 12.24 & 11.67 & 11.68 & 11.69 & 11.69 \\
\hline 6 & 12.55 & 12.13 & 11.54 & 11.55 & 11.57 & 11.6 \\
\hline 8 & 12.34 & 11.30 & 10.12 & 10.15 & 10.9 & 10.9 \\
\hline
\end{tabular}


TABLE 9. Color strength and fastness properties of printed untreated and air plasma treated cotton fabric under different condition of plasma exposure time and discharge power.

\begin{tabular}{|c|c|c|c|c|c|c|c|c|c|c|c|}
\hline \multirow{2}{*}{$\begin{array}{c}\text { Discharge } \\
\text { power } \\
\text { (watt) }\end{array}$} & \multirow{2}{*}{$\begin{array}{c}\text { Time of } \\
\text { treatment } \\
(\mathrm{min})\end{array}$} & \multirow{2}{*}{$K / S$} & \multicolumn{2}{|c|}{$\begin{array}{l}\text { Washing } \\
\text { fastness }\end{array}$} & \multicolumn{2}{|c|}{$\begin{array}{l}\text { Rubbing } \\
\text { fastness }\end{array}$} & \multicolumn{4}{|c|}{ Perspiration fastness } & \multirow{2}{*}{ Light fastness } \\
\hline & & & Alt. & St. & dry & wet & \multicolumn{2}{|c|}{ acid } & \multicolumn{2}{|c|}{ alkali } & \\
\hline \multirow{5}{*}{$\overrightarrow{0}$} & . & 100 & 5 & 5 & 54 & 54 & 5 & 5 & 5 & 5 & $6-7$ \\
\hline & 1 & 11865 & 5 & 5 & 54 & 54 & 5 & 5 & 5 & 5 & 76 \\
\hline & 5 & 121.72 & 5 & 5 & $4-5$ & 5 & 5 & 5 & 5 & 5 & 76 \\
\hline & 10 & 124.45 & 5 & 5 & $4-5$ & 5 & 5 & 5 & 5 & 5 & 76 \\
\hline & 15 & 125.38 & 5 & 5 & $4-5$ & 5 & 5 & 5 & 5 & 5 & 76 \\
\hline \multirow{4}{*}{ ?. } & 1 & 119.4 & 5 & 5 & $4-5$ & $4-5$ & 5 & 5 & 5 & 5 & $6 \_7$ \\
\hline & 5 & 121.87 & 5 & 5 & $5 \_4$ & $5 \_4$ & 5 & 5 & 5 & 5 & $6 \_7$ \\
\hline & 10 & 124.99 & 5 & 5 & $4 \_5$ & $4 \_5$ & 5 & 5 & 5 & 5 & $6 \_7$ \\
\hline & 15 & 125.5 & 5 & 5 & $5 \_4$ & 5_4 & 5 & 5 & 5 & 5 & 5_6 \\
\hline \multirow{4}{*}{$\stackrel{+}{0}$} & 1 & 120.01 & 5 & 5 & $4-5$ & $4-5$ & 5 & 5 & 5 & 5 & $6 \_7$ \\
\hline & 5 & 122.98 & 5 & 5 & $5 \_4$ & $5 \_4$ & 5 & 5 & 5 & 5 & $6 \_7$ \\
\hline & 10 & 125.68 & 5 & 5 & $4 \_5$ & $4 \_5$ & 5 & 5 & 5 & 5 & $6 \_7$ \\
\hline & 15 & 125.54 & 5 & 5 & 54 & 54 & 5 & 5 & 5 & 5 & $5 \_6$ \\
\hline
\end{tabular}




\section{References}

1. Rino Morent, Nathalie De Geyter, Johan Verschuren, Karen De Clerck, Paul Kiekens, and Christophe Leys. "Non-thermal plasma treatment of textiles." Surface and coatings technology 202, no. 14, 34273449 (2008).

2. Tataina Yuranova, A. G. Rincon, A. Bozzi, S. Parra, C. Pulgarin, P. Albers, and J. Kiwi. "Antibacterial textiles prepared by RF-plasma and vacuumUV mediated deposition of silver." Journal of Photochemistry and Photobiology A: Chemistry 161, no. 1, 27-34 (2003).

3. Marie Jérôme Tsafack, and Joëlle LevaloisGrützmacher. "Flame retardancy of cotton textiles by plasma-induced graft-polymerization (PIGP)." Surface and coatings technology 201, no. 6, 25992610 (2006).

4. Marie Jérôme Tsafack, and Joëlle LevaloisGrützmacher. "Towards multifunctional surfaces using the plasma-induced graft-polymerization (PIGP) process: Flame and waterproof cotton textiles." Surface and coatings technology 201, no. 12, 5789-5795 (2007).

5. G. Buyle, "Nanoscale finishing of textiles via plasma treatment." Materials Technology 24, no. 1, 46-51 (2009).

6. Sebastien Guimond, Barbara Hanselmann, Martin Amberg, and Dirk Hegemann. "Plasma functionalization of textiles: specifics and possibilities." Pure and Applied Chemistry 82, no. 6, 1239-1245 (2010).

7. Hsiang-Jung Tseng, Shan-hui Hsu, Mien-Win Wu, Tien-Hsiang Hsueh, and Pei-Chi Tu. "Nylon textiles grafted with chitosan by open air plasma and their antimicrobial effect." Fibers and Polymers 10, no. 1, 53-59 (2009).

8. Qufu Wei, ed. Surface modification of textiles. Elsevier, 2009.

9. M. Radetic, P. Jovancic, N. Puac, and Z. Lj Petrovic. "Environmental impact of plasma application to textiles." In Journal of Physics: Conference Series, vol. 71, no. 1, p. 012017. IOP Publishing, 2007.

10. Mohammad Mokbul Hossain, Dirk Hegemann, Giuseppino Fortunato, Axel S. Herrmann, and Manfred Heuberger. "Plasma Deposition of Permanent Superhydrophilic a-C: H: N Films on Textiles." Plasma Processes and Polymers 4, no. 4, 471-481 (2007).

11. Iva Rezić, Michaela Zeiner, and Ilse Steffan. "Determination of 28 selected elements in textiles by axially viewed inductively coupled plasma optical emission spectrometry." Talanta 83, no. 3, 865-871 (2011).

12. Richard Blackburn, ed. Sustainable textiles: life cycle and environmental impact. Elsevier, 2009.

(Received 28/10/2019; accepted $1 / 11 / 2019$ )

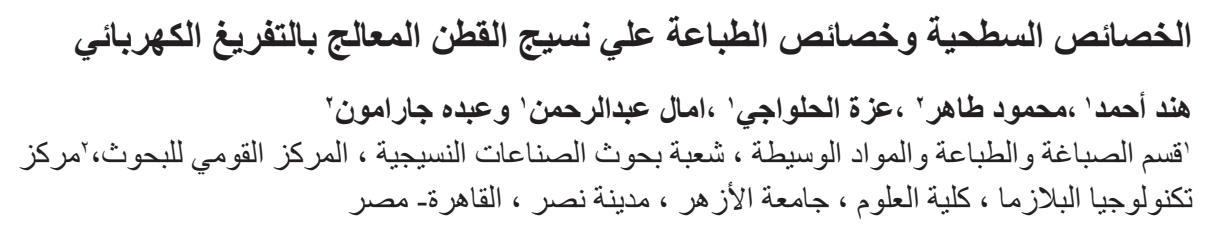

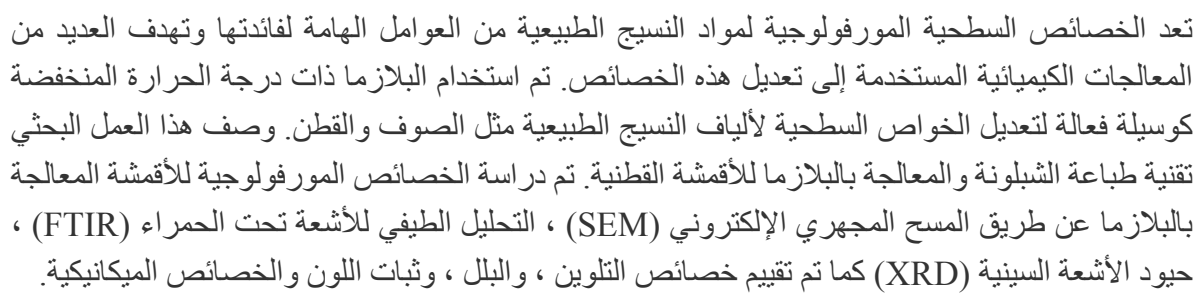

